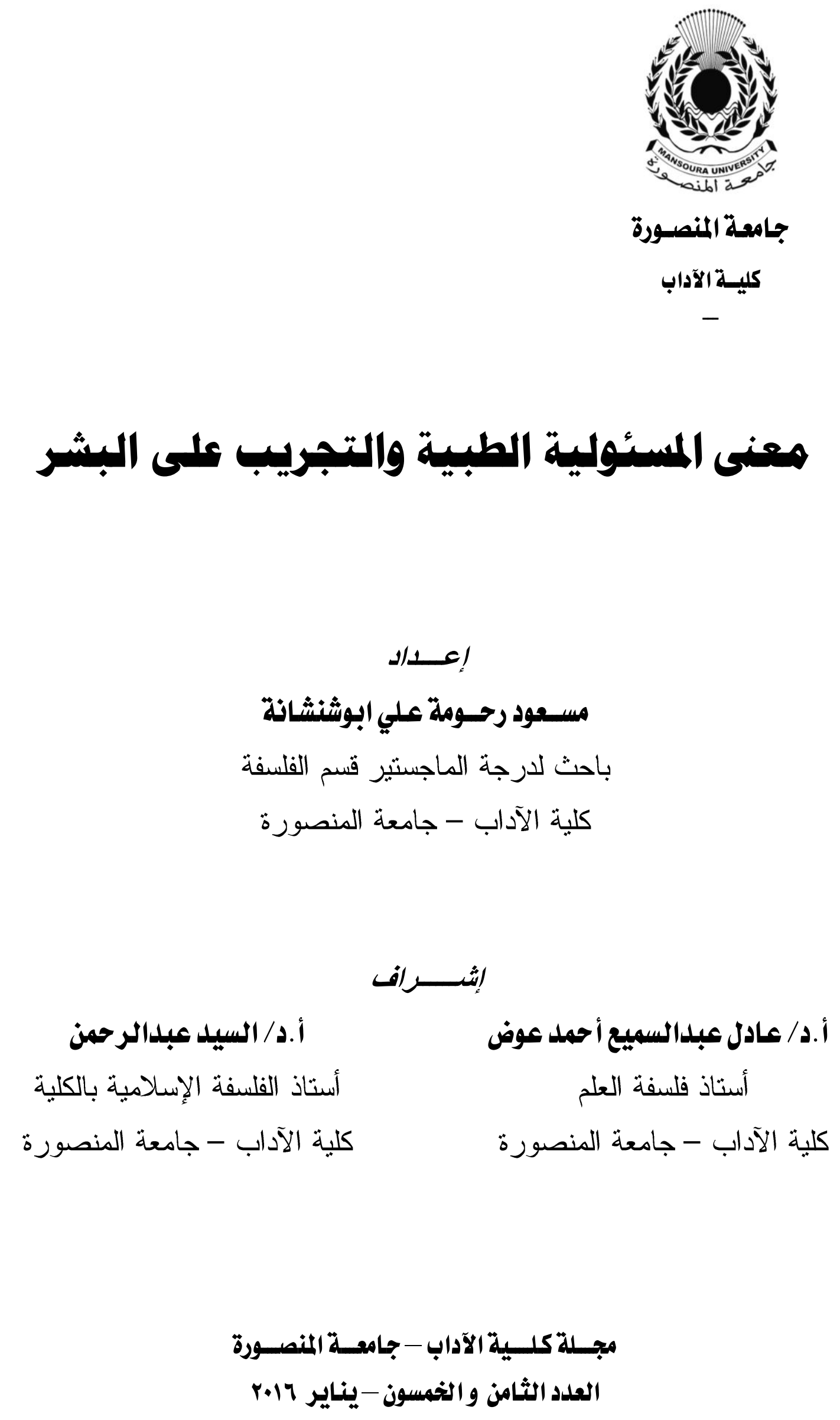




\section{معنـى المسئولية الطبية والتجريب على البشر}

\section{مسعود رحسومة علي ابوشنشانة}

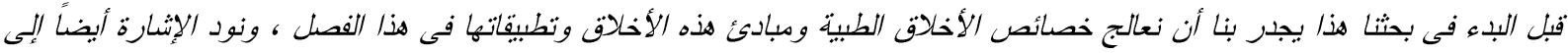

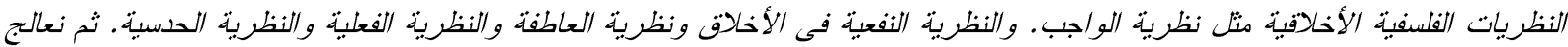

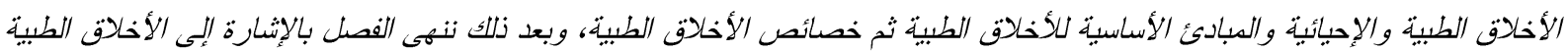

$$
\text { بين الرفض و القبول ثم الخوض فى الأخلاق الطبية فى القرن العشربن. }
$$

\section{Abstract}

Before you start this in our research we are worthwhile to address the characteristics of medical ethics and principles of this ethics and its applications in this chapter, and we would like to also point out the moral philosophical theories such as the theory of duty. And in the utilitarian theory of morality and emotion theory and the theory of actual and theoretical intuitive. Then treat bio-medical ethics and the basic principles of medical ethics and medical ethics properties, and then finish the chapter with reference to medical ethics between rejection and acceptance and then go into medical ethics in the twentieth century.

ثمة موضوع يشغل بال كبار علماء

المقلدمــة

الطب المتفلسفين ، وهو أنهر حريصون على تقدم علم الطب وابتكار الطرق المتطورة فى علاج المرضى سواء فى تقنية العمليات الجراحية المختلفة أو فى اكتشاف الأدوية الجديدة ، لكن ذلك غير ممكن الا بالتجريب ، وسيكون

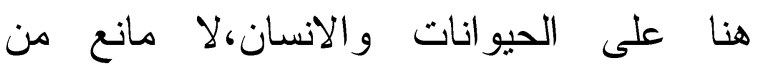
التجريب على الحيوان لكن تجريينا على الانسان قد يعرضه للآلام وقد نضحى بصحته أو بحياته. وهنا تتشأ مشكلة خلقية: هى أننا فى جعلنا الإنسان موضوع تجريب اعتبرناه الة لا حياة فيها او ان حياته رخيصة يمكن التضحية بها فى سبيل تقدم الطب. ويجد علماء الطب فى هذا الموقف حيرة ومأزقا، فمن جهة نحن حريصون على تقدم الطب ولن نتقدم الا بالتجريب على الانسان الحى،"لكن من جهة هذا التقدم والتجريب يعرض حياة بعض الناس للخطر ، هل نضحى بحياة بعض الناس فى سبيل تقدم علم الطب أم نضحى بتقدم الطب فى سبيل الحفاظ على قدسية حياة البشر؟ وبعبارة أخرى كيف نتقدم فى علم
يرسم هيرمان ويجودسكى وسوكير هوب ارتقاء المبادئ الاخلاقية الحاكمة للابحاث على البشر · فهما يتببعان أصل شفره نومبرج الخاصه بممارسات الباحثين المشهورين فى معاملهم ، و الخطوط العريضة المؤسسة ، بشكل ساخر ، فى المانيا نفسها. تم تعديل هذه الخطوط العريضة من خلال اعلان هلنسكى ومن خلا تطوير مؤسسات المراجعة فى الولايات المتحدة ومجتمعات ابحاث الاخلاقيات المقارنة فى دول اخرى. وما زالت المشكلات موجودة بسبب التنوع بين المجتمعات و البلاد و عدم التوافق بشأن المواضيع الاخلاقية المحيطة بالابحاث على الجينات، المرض العقلى ، الايدز، خلل الاعاقة والوشم. يؤكد الكتاب على ان تتظيم الحكومة للابحاث التى يكون البشر مواضيعها يمكن ان تثأثز اذا تم الحفاظ على اعتبارات الحالة المحلية و التطبيق المرن (') 
يمكن لنا جميعاً ان نكون ليوماً

موجودين داخل بروتوكول من البحث: سواء فى حالة مرض (أغلب المرضى المصابين بالسرطان او الايدز منخرطين اليوم فى بروتوكولات تجريبية ، وينطبق الامر على الثى امر اض اخرى كثيرة). او حتى لاننا ، رغم عدم

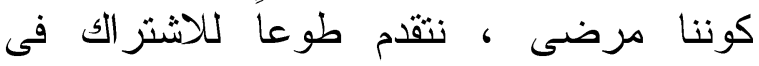

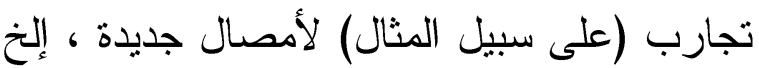
، وبحسب تقدير لوزارة الصحة الفرنسية ، بتاريخ 1997 ، يوجد فى فرنسا،- فى- البحث البيولوجى الطبى وحده- على الاقل .... 10.

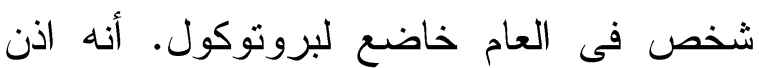

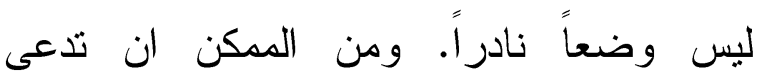
للمشاركة فى "لجنة استشارية لحماية الاشخاص لاصن فى البحث البيوطبى": وهو الاسم الفرنسى للجان اخلاق البحث التى تفحص البروتوكولات قبل تطبيقها. ما الذى يجب ان يعرفه كل مواطن بخصوص البحث العلمى على الكائن الانسانى ، لإنى

كى يمارس حقوق المو اطنة وو اجباتها؟(") استخدام البشر فى البحث الطبى لهى

البيولوجى ربما برجع الى بدايات الطب نفسه ، لكن الاهتمام الاجتماعى بأخلاقيات استخدام البشر كمواضيع للبحث لم يكن الاهتمام الاولى بلى الإنى

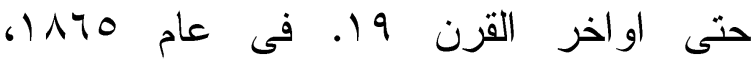
كلودبرنارد، استاذ الفسيولوجى فى السوربون، باريس، كتب اطروحه كلاسيكية عن علم التجربة السربرية. قال برنارد ان الاطباء لا لا لاعل يجب ان يجروا تجارب على البشر يمكن ان تكون ضارة الى اى حد، حتى اذا كانت النتائج
الطب مع احترام حياة الناس؟ كان ينبنى أن نتناول هذا الموضوع حين نتناول أخلاقيات الطبيب ، لكن تبريرنا لتتاوله فى هذا الفصل أن

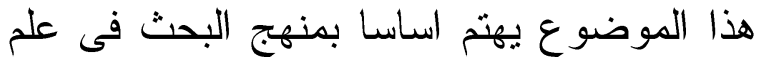
الطب، ومناقشة المسلمات التى يبدأ منها علم الطب ، و المسلمة هنا هى ان الانسان كائن يجب احتر امه وتقديس حياته و المحافظة عليه ، لدرجة اننا مستعدون للتضحية بالتقدم فى الطب فى

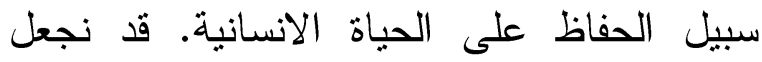

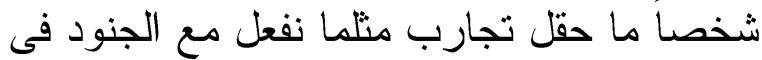

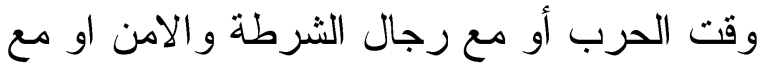
رجال الاطفاء وبعض عمال المصانع ، لكن هذه استثناءات من القاعدة التى نسلم بها وهى أننا يجب الا نضحى بشخص فى سبيل أشخاص

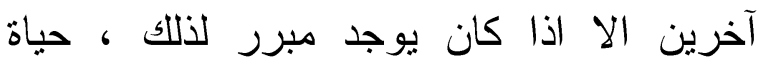
الانسان ليست سلعة تباع وتشترى و انما هى قيمة خلقية مطلقة يجب الحفاظ عليها. من المقبول أن نقتل بقرة واحدة وأن يشرح جسمها لمنع انتشار مرض فيها بين سائر البقر، لكن لا يمكن تطبيق هذا العمل على الانسان (؟).

\section{طبيعـة التجـريب على البشـر :}

موضوع التجريب الطبى من اهم الموضو عات المتصلة بالممارسة الطبية فالتجربة على الانسان فى الدواء وفى العلاج امر حتمى لإله لانه لا ينفع التجربة على الحيوان فقط. ومع حتمية وضرورة التجربة على لئ المرضى ظهرت لنا مشكلة وهى كيف يمكن لنا ان نحافظ على الاثخاص البسطاء الذين يكونون محل التجربة دون رضاهم. 
تراءت للمجتمع على انها حامية للبشر محل

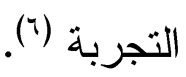

أمام هذه المشكلة و الحيرة حاول بعض

كبار علماء الطب المتفلسفين وضع معايير تقيس

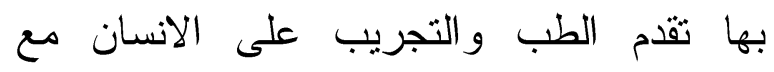
الحفاظ على كر امة الانسان واحتر ام حباته ، وقد الجدان جعلوها ثلاثة انواع من المقاييس أو المعايير

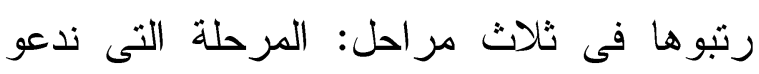

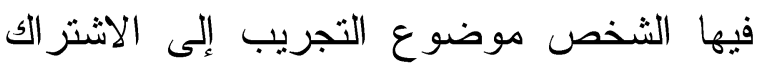
فى التجربة ، و المرحلة التى تقوم فيها علاقة بين

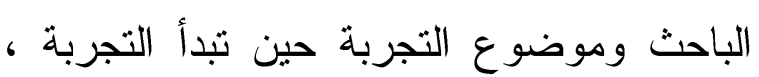
و المرحلة التى تتم فيها العلاقة بينهما بعد انتهاء التجربة ، ونفصل فيما يلى معايير كل مرحلة.

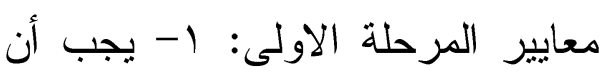

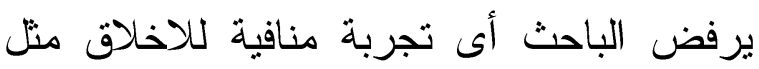

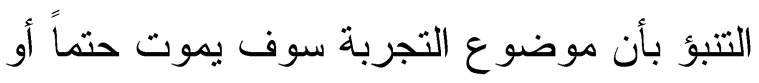
يفقد أحد أعضائه أو أطر افه ، أو أى حالة عقلية.

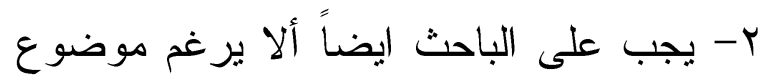
التجربة على قبول العلم تحت ضغط مثل اغر ائه

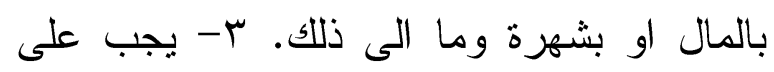
الباحث ان يصوغ التجربة صياغة علمية دقيقة.

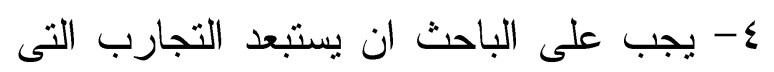

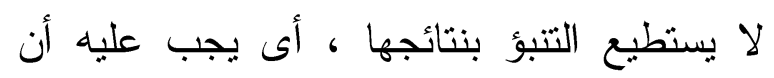

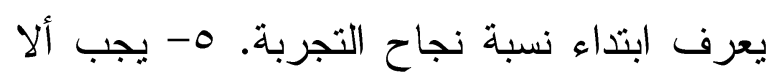
ينفرد باحث واحد بصياغة التجربة و إنما يشترك فريق من الباحثين فى صياغتها ويتفقون فيها جميعاً (v) جزئ

معايير المرحلة الثانية وهى العلاقة بين الباحث وموضوع التجربة فى بدء التجربة:
ذات الهمية للعلم او صحة الاخرين. رسمت اطروحته الطرق التى يجب بها تتظيم التجارب التهب

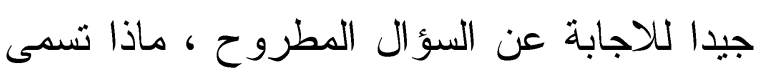
"الطريقة العلمية"(£). إن التجريب الانسانى موجود ، كان

كلود برنار (111) Claude Bernard ( AVA تجريبياً: وقد كان. حمل باستور Pasteur

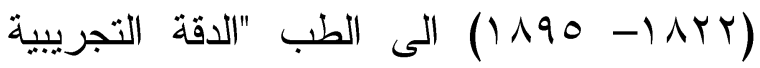
للكيميائى". و اتخذت فكرة الطب العلمى مسار ها.

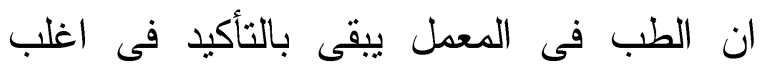
الاحيان طب "حيوان التجريب Cobaye

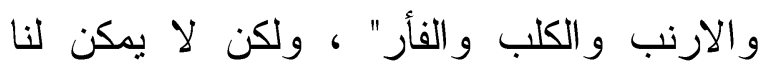
دائمًا أن نطبق نتيجة الحيوان على الانسان. هناك اذن تجارب اجريت على الانسان "بهدف

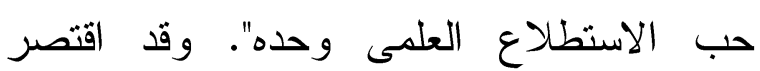

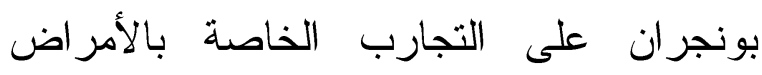
المعدية ، وبحث عن تقاريرها فى الصحف الطبية. فهذه التجارب بالفعل لبست خفية: بل هى

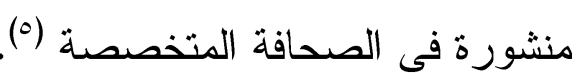
مع بدء النظرية الجرثومية للمرض فى النى القرن 9 1، تتامت التجارب الطبية البيولوجية. مع ذلك كان هناك اهتمام اجتماعى قليل بشأن اخلاقيات مثل هذه التجارب ، وفى الحقيقة ، ظهور الاهتمام الاخلاقى كان فى بعض الاحيان خطيرة فى عام 19.91، الروسى ، سميدوفيش، نشر كتاب يصف التجارب البشرية السافرة

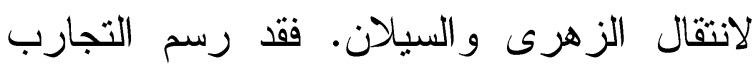
على انها "مبادىء غريبة للعلم" و "تعصب" علمى ولى رسئ 
أو الاشادة به فى المجلات الدورية التى تسجل تقارير عن التجارب ، لكى يشعر هذا الشخص أنه أسهم مع الباحث فى تقدم علم الطب وأسهر فى خير الانسانية (^). وهناك جها مهر من التفكير الأخلاقى قد تم منذ الحرب العالمية الثانية ، يوجد اليوم أخلاق للبحث العلمى على الانسان ، مسجلة فى نصوص مرجعية قومية و عالمبة. هل يوجد اطار قانونى لممارسات البحث؟ تتعدد الحلول من بلد إلى آخر • فى بعض البلاد يرجع التشريع الى توصيات لجان الاخلاق ، وبلاد اخرى لجأت الى وضع قو اعد ، وفى لَّ فرنسا تم اصدار قوانين. على أى حال ، فى جميع البلاد تقريبا اليوم ، تخضع بروتوكولات

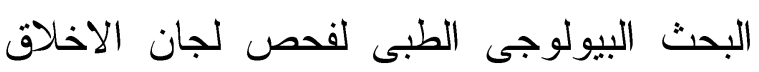
والبحث فى المستشفيات أو فى المحليات قبل تطبيقها.

يوجد نوع من الاشراف الديموقر اطى على طريقة البحث ، التى جعلت البحث يخرج من وضع شبه السرية الذى تطور فيه منذ قرن

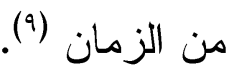

أثناء النصف الاول من القرن .ب، المدارس الطبية فى امريكا اعتمدث بشكل كبير على المستشفيات الخيرية لتقدم مرضى يتعلم عليهم الطلاب. استخدام مرضى المستشفيات الخيرية للتجارب تم تبريره كوسيلة من المريض لرد جميل المجتمع انه يقوم برعايته صحيا عن طريق وهب جسده لتطور العلم ، وبناء عليه ، تطور الجنس البشرى كله. كان هناك بعض
(- لا مانع من استخدام شخص ما موضوع تجربة فى سبيل مصلحة الناس الآخرين بشرط أن يكون متطوعاً بالمعنى الدقيق أى بشرط أن يكون حراً مختاراً فى قبول هذا الدور ، وفى لهى هذه الحالة يجب أن يعرف هذا الشخص هدف التجربة و أن تقال له للك المخاطر المحتملة. وله أن يقبل او يرفض ، ويجب ألا يكون مضطراً بأى معنى للإضطر ار مثل تهديد أو مكافاة. r- يجب على الباحث أن يحافظ على كيان الشخص موضوع التجربة وكرامته وسلامته وحياته ، وكان الباحث يسأل نفسه عما اذا كان يعد نفسه لقبول هذا الدور لو طلب منه، فاذا كان جوابه بالسلب فالاخلاق تحتم عليه ألا يستخدم أى شخص كموضوع للتجريب ، بيجب أن تتم هذه العلمية فى العلانية وليس فى الخفاء وفى وضوح وصر احة بحيث لا تتم فى سجن أو فى مصحات المعوقين ، وجوهر هذا المعيار أن يكون استخدام الانسان كموضوع تجريب متفقاً و القبول العام و الر أى العام. أما معايير المرحلة الثالثة التى تتعلق بالعلاقة بين الباحث و الشخص موضوع التجربة بعد ادائها فهى كما يلى: ا- يجب على الباحث أن يتابع احتمال المخاطر لدى موضوع التجربة ، فمثلاً يجب معالجة موضوع التجربة اذا اصيب بأذى ، ومكافأته وتعويضه ، وحينئذ يجب أن تكون الدولة هى المسؤولة عن هذا العلاج. rإذا كان التجريب على افراد الناس عملاً انسانياً فيجب أن يحظى الشخص بشكر الباحثين بعد انتهاء التجربة بوسائل عديدة مثل خطابات الشكر 
العو ائق الاخلاقية القليلة على البحث فى هذا وجه فى وسط بحتوى الصفراء ، افترض ايفى الوقت ، معظم الباحثون الطبيون اعتبروا ان التيفود انتقل من اشخاص نمى لديهم الجرثوم اشخاص ذوى ارادة جيدة يريدون مصلحة بشكل مزمن فى الحويصلة المرارية، بما ان المريض ، كما رأها الباحثون ، الهذف المرض استشرى فى المستشفيات العقلية ، فإن المرضى النفسيين كانو ا مجتمع مثالى للدر اسة. الاساسى. رغم أن المشاركين من المرض كانوا "متطو عين" فإن هناك بعض الأسئلة مثل اذا كان يمكن السماح لمثل هذه التجارب فى الوقت الحالى بناء على اختصاص المريض وقدرته على اعطاء استجابة "صحيحة". بحلول الحرب العالمية الثانية وتعريف عدد كبير من الامراض الوبائية والامراض المرتبطة بالحرب ادى ذلك إلى ثركيز جهود البحث العسكرى و المدنى على هذه الحالات. من اخطر الامر اض ، كان الملاريا الاشهر، و البحث عن ادوية مضادة للملاريا استرعى كثير من الانتباه. بنهاية الحرب ، تم جمع مئات الادوية و الكيماويات، واستخدمت فيما بعد فى البحث عن علاج للسرطان. أمثلة على الدراسات الفسيولوجية غير المضرة لكن مهمة كانت تلك

عن العش الليلى وعمى الالوان ('). أثناء الحرب العالمية الثانية ، خدم هـ.و كضابط منفذ فى قسم البحث فى مكتب الجراح الجوى فى سلاح الجو وكان منشغل فى عام 9 وا، بدأ أحد العلماء فى ادارة التجارب على اثار الارتفاعات الصورية فى العملية التنفسية فى المتطوعين البشريين تحت اشر اف اندروايفى فى معامل الفسيولوجى فى كلية الطب جامعة نورثويسترن ، تجارب الارتفاعات كانت بعض من الدراسات العديدة المختلفة التى كان فيها البشر محل دراسة والتى أديرت فى معامل ايفى عبر السنون لم يكن هنالك معيار رسمى لحماية البشر الخاضعين للتجربة ، لكن أصر إيفى ألا تتم تجربة فى المعمل إلا إذا

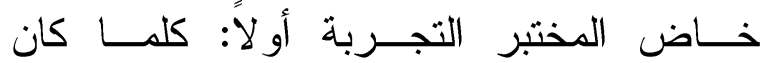
متاح أو ملائم ، لم يتم خضوع البشر لاى تجربة فى معامل إيفى إلا بعد در اسات مستفيضة على الحيوانات. تم اعطاء شرح كامل - الفرض محل الاختبار، النتائج على الحيوان ، مفهوم التجربة، الاجراءات المتبعة ، و المخاطر المحتملة - لكل متطوع ، و الأى عادة ما يكون عضو الفريق أو الجامعة ، طالب طب ، أو مل

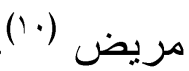
بتعريف و استكشاف علاقات الالة البشرية و البيئة البشرية. من خلال واجهات المجموعات التنفيذية إهنمام إيفى بأخلاقيات البحث كان جدير بالثناء لمرات عديدة ، لكن نوضح أنه ار اد العديدة مثل التسلح ، محصلات ، محصلات

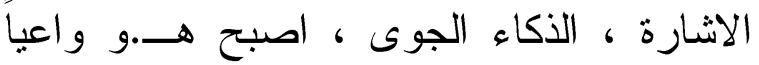
ايضا تجارب على مرضى فى مستشفى الامراض العقلية لدراسة انتقال حمى التيفود. باكتشاف ان جرثومة التيفود تتمو على أفضل بشأن البحث الذى يدار فى المانيا والذى كان 
نهايته الموت. مستشارة ايفى كان مدير مدنى فإن تصريح الالمان بأن اليهود ، الجنسيات

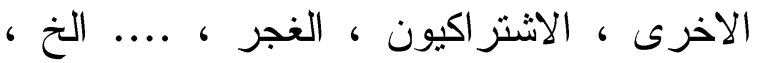

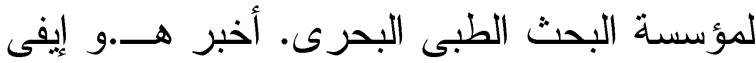
كانو ا "لا شىء" ، جعلت من الممكن للاصوات بشأن بشاعات البحث فى المانيا والتى سمح العلمية الاخرى بعمل ادار ات بحث محل تساؤل على اعضاء من هذه المجموعات ، لم يتم تغطية هؤلاء الافراد بالارشادات الاخلاقية الالمانية

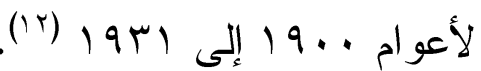
فى محاكمة جرائم الحرب العالمية

الثانية الخاصة بالاطباء النازيين ، تم تبرأة متهمين ، وتم الحكم على V بالإعدام ، وحكم

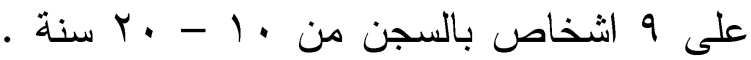
كان هناك دليل على الجريمة ضد آخرين لكن لم تكن هناك امكانية لمحاكمته ، لاسباب تقنية او اعذار • تم مساعدة البعض (بطريقة غير شرعية) عن طريق جيش الو لايات المتحدة ليأتو اللو لايات المتحدة ، حيث يمكن استخدام "معرفتهم" فى " المختبرات العسكرية. ثم نقل أن أحد الاشخاص هـ كان هو المحفز للتجارب الغير مشهورة لدواء فعال لعلاج الهلوسة ، مهلوس بتأثير ات مختلفة ، فى در اسات لوكالة الذكاء المركزية. ثم نقل أن بعض الافراد انزلقوا فى دواء علاج الهلوسة بدون معرفة أو مو افقة منهم.

كتب جورج اناس أن ثركيز المجلس كان على الطبيعة الإجر امبة للتجارب النازية ، لكن القضاه كانو أيضا يمسكون باهنمامات اخلاقية أكبر بخصوص البحث الطبى. بحثت المحكمة عن إطار عمل تاريخى للمعايير الطبية يمكن من خلالها محاكمة الاطباء النازيين ومحاولة تفسير نطاق التجارب الطبية التى قام

خلال الذكاء البحرى والذى اكد التقارير.

\section{التجــارب النـازبــة والبحث العلمىى:}

انتشرت تدريجيا بانتهاء الحرب. فى

عام 9 1 1 ، أدارت الولايات المتحدة تجميع جر ائم الحرب الثانية لبعض الاطباء النازيين المشاركين فى البشاعات فى الولايات المتحدة ضد كارل براندت (طبيب هنلر الشخص) وجهت تهم لـ ک Y متهمًا. كان إيفى معروف عالميا بوصفه باحث بشرى ، كان اختيار منطقى للتعبين عن طريق المنظمة الطبية الامريكية لسكرتير الحرب كثاهد لصالح امريكا فى

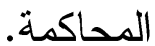

من المثير ملاحظة انه فى عام .. 19 ، قبل التجارب النازية ، أمر الوزير ابروسى للشئون الدينية ، التعليمية ، و الطبية مدراء العيادات بتحديد المشاركة فى التجارب الطبية على البالغين المؤهلين الر اغبين فى المشاركة بعد اطلاعهم بشكل كامل على العو اقب المحتملة. كل مدير عيادة يسمح بشكل مستقل بالتجارب لكن يجب عليه الاحتفاظ بسجل الاستجابة مع ارشادات الوزير فى عام اسوا ، ونتيجة ، اتهامات صادرة فى الصحافة باستغلال البشر الوزير الالمانى للشئون الداخلية نشر محددات استخدام العلاجات الحديثة والتجارب البشرية التى بقيت معلقة اثناء الرايخ الثالث. مع ذلك 
يكون على نمط واحد فى كافة التجارب الطبية ، فمن السهل الحديث عن التطبيقات الإكلينيكية على الحيو انات بالنسبة لتجارب العقاقير والأدوية الطبية. أما فى غير هذا النطاق من التجارب فإن الأمر يثير قدرًا من الصعوبة قد تعرقل النشاط لـاط

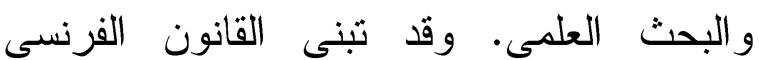
اتجاها الى تشجيع البحث وبالتالى التجارب ، ومن هنا كان تعبير المشرع الفرنسى مرنا عندما طلب "أن تكون التجارب التطبيقية كافية". وبذلك يكون المشرع الفرنسى قد تغاضى عن انثتر اط أن تكون التجارب على نحو معين مكتفيا بصفة عامة بأن تكون هناك تجارب تطبيقية كافية. وهو اتجاه استهدف المشرع الفرنسى من ورائه عدم التشدد فى القيود سعيا إلى التوسع فى تشجيع التجارب العلمية و الطبية(10).

وأدى ذلك الى قيام الدول الاوربية

بوضع معاهدة تهدف الى فرض قيود على مثل

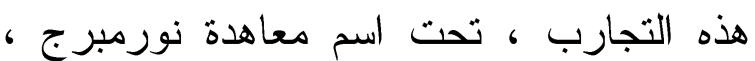
كان من أهم بنودها ، ألا تتم التجربة ألا بعد أند موافقة الشخص موضوع التجربة ، بمعنى أن تكون لديه مقدرة قانونية وعقلية على رفض أو قبول هذه التجربة دون تدخل أى عامل خارجى يمكن أن يؤثر على قراره. "ولابد أن تؤدى التجربة إلى نتائج تهدف إلى خير المجتمع" ، ويجب ألا تستمر اى تجربة حين يكون هناك لإك

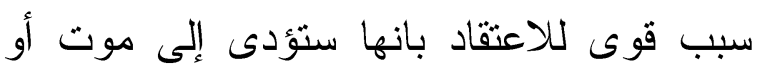

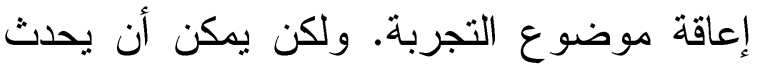

بها النازيون ، واطباء أخرون وعلماء ، اثثاء الحرب العالمية الثانية (r'). إننا نتفق بشكل عام حول أهمية وقيمة السبطرة على الأمر اض والأوبئة و التخلص منها. ولكن الثقام فى هذا المجال يعتمد أساسا على البحوث والتجارب التى يجب أن تجرى سواء على الحيوان او الانسان. أما بالنسبة للحيوان التهان فإن استخدامه ما زال مستمر ا رغم اعتراض جمعيات الرفق بالحيوان. ولكن المشكلة الحقيقية تكمن فى اجر اء التجارب على الانسان ، خاصة إذا عرفنا ان مثل هذه التجارب تحتاج إلى دعم مادى من قبل الحكومات و المجتمعات. لذلك إلك ظهرت مواقف تزداد تصلبا تجاهها ، "وخاصة بعد الحرب العالمية الثانية حين تم فضح مساوئ مثل هذه التجارب فى محاكمات نورمبرج عام Q \ ام. كرد فعل ضد التجارب التى أجرتها ألمانيا النازية على المعتقلين فى ذلك الوقت"(\{ء (). ويلاحظ أن شرط سبق إجراء تجارب كافية يقصد به إجراء التجارب ونجاحها على

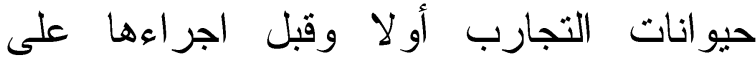
الانسان. وقد أكدت هذه الضرورة لجنة (أخلاق المهنة) فى فرنسا منذ عام بر9 ام حيث قررت "أنه لا يمكن اجراء التجارب على الانسان قبل الحصول مسبقا على كافة الضمانات الخاصة بنجاح التجربة بإجراء أبحاث معدلية وعلى لهئ انواع متعددة من الحيوانات ثم الحصول على بلى لثراه قدر كاف من النتائج الفعالة". غير أن تحديد نطاق هذا الثرط الأخير قد يثير بعض الجدل وذلك لأن الأمر لا لأل 
و المستتيرة و المعتمدة لهذا الشخص بعد أن يقوم المجرب أو الطبيب الذى يمثله بتعريفه

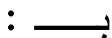

- هدف البحث ، ومنهجه ومدته.

- الفو ائد المنتظرة ، العوائق و المخاطر

المتوقعة ، متضمناً حالة ايقاف البحث

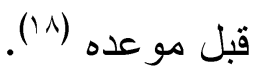

ץ- يجب تصميم التجربة لتؤدى لنتائج مثرة لصالح المجتمع ، و لا يمكن الوصول اليها عن طريق وسائل اخرى أو طرق اخرى للار اسة وليست بعشو ائية او غير

$$
\text { ضرورية فى طبيعتها. }
$$

ب- النتائج المتوقعة للتجربة يجب أن تبرر

$$
\text { أدائها. }
$$

ع- يجب ادارة التجربة لتجنب المعاناة والالم

$$
\text { الجسدى و العقلى. }
$$

- لا يجب ادارة اي تجربة يكون هناك أى

سبب مسبق للاعتقاد أنها تثؤدى إلى لى

$$
\text { الاعاقة أو الوفاة. }
$$

צ-درجة المخاطرة لا يجب أن تتعدى الأهمية الآدمية للمشكلة التى تقوم

$$
\text { التجربة بحلها. }
$$

V- يجب حماية الشخص الخاضع ضد أى ضرر خارجى محتمل أو إصابة أو إعاقة

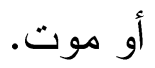

ᄉ- يجب ادارة التجربة فقط من قبل اشخاص

$$
\text { مؤ هلين علمياً. }
$$

9- أثناء التجربة ، يجب أن يكون للشخص

$$
\text { الخاضع للتجربة حرية إنهائها. }
$$

ذلك إذا كان الباحث أو الطبيب ، هو نفسه موضوع التجربة (17).

إذن حاولت المحكمة وضع بعض

المبادئ للتجارب البشرية والتى يمكن أن تخدم كثفرة لأخلاقيات البحث. إن إيفى وليو الكساندر ، و عالم أعصاب فى بوسطن وطبيب نفسى كانو ال ايضًا شهودًا فى المحاكمة ، كانوا مؤثرين فى صياغة اخلاقيات البحث تللك ، عن طريق ترتيب شهادتهم كسلسلة مبادىء يمكن استخدامها عن طريق القاضى فى قراره الاخير يبدو أن هذه المبادئ أتت من مصادر كثيرة ، لكن وصفنا السابق للاجراءات المستخدمة فى معامل إيفى يعطى اقرار للمعتقد أن ما أصبح يعرف بشفرة نومبرج هو انعكاس للمعايير الشخصية لهذا

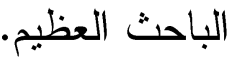

\section{مبـادئ شفـرة ذومبـرج :}

1- المو افقة الاختيارية للشخص الخاضع للتجربة ضرورية ، يجب أن يكون لدى الفرد القدرة القانونية للمو افقة و المعرفة الكافية و الفهر لطبيعة التجربة و المخاطر المتضمنة لاتخاذ قر ار مستنير (IV) - (IV). إذن أول الشروط التى تسمح بإجراء البحث:

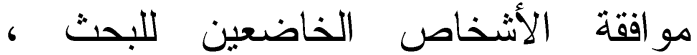
وينص على ان تكون هذه الموافقة كتابية بقدر الامكان. و النص يضع اقتضاءات صارمة حول طبيعة المعلومات التى يجب أن يتلقاها الاشخاص: قبل إجراء بحث بيولوجى طبى على شخص ينبنى الحصول على الموافقة الحرة 
العلمى لانها تضع حدودا لمناهجنا فى دراسة

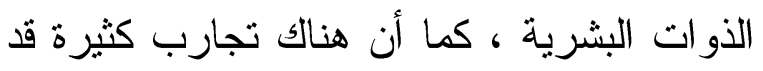
لا يمكن اجراؤها لأننا نعتبرها لان لا أخلاقية.

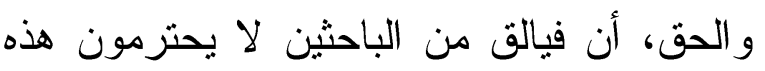

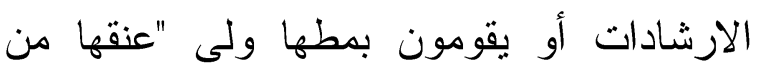

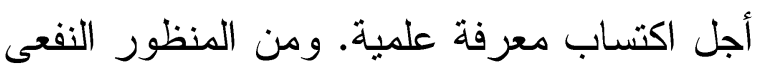

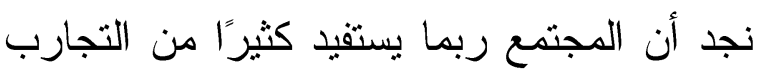
التى تتنهك حقوق وكر امة عدد قليل من الافر اد.

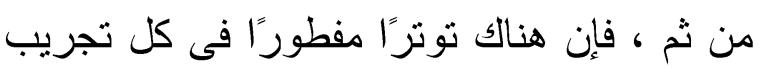

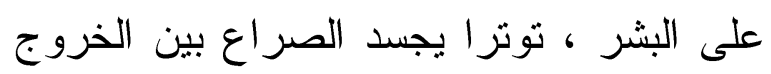
بنتائج جيدة للمجتمع وبين حماية الافراد (r.).

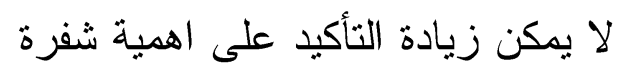

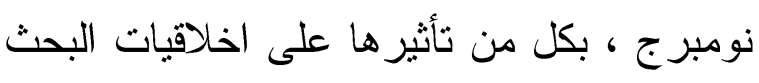

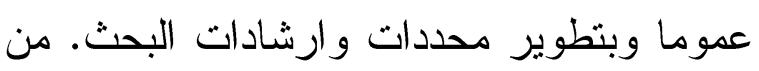

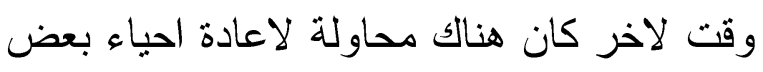

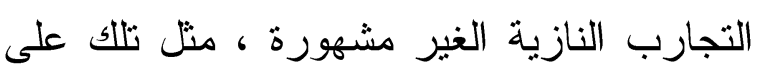

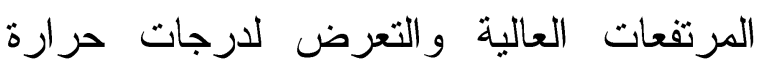

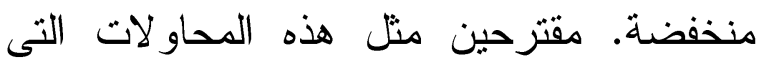

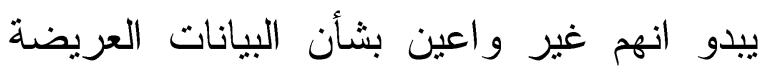
التى ينم اكتسابها عن طريق الدراسات الددنية

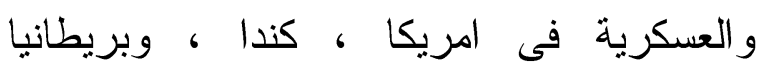

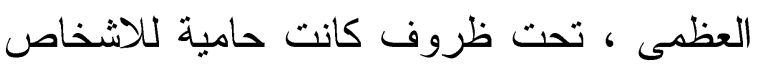

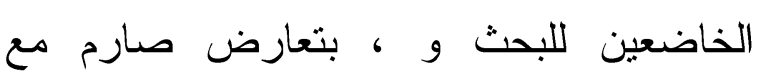
النازيين ، لم بستخدموا الموت كنهاية. محاو لات

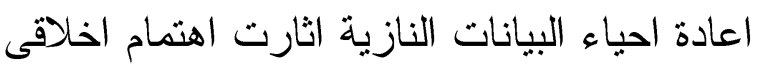

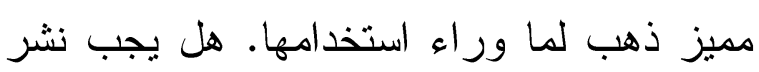
البيانات الناتجة عن دراسة غير أخلاقية أو دهاب استخدامها بأى شكل؟ هل من المسموح استخدام مثل هذه البيانات اذا لم يكن هناك بيانات ذلئ ذات
•

الذى يقوم بالتجربة مستعد لانهائها فى أى وقت وأى مرحلة ، إذا كان

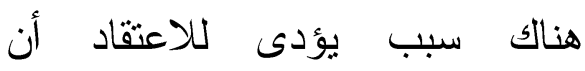

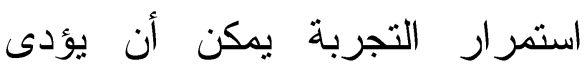

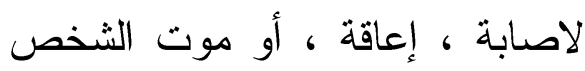
الخاضع للتجربة (19).

و اليوم تتضمن كل المؤسسات البحثية تقريبًا وكثير من الشركات الخاصة هيئة مر اجعة مؤسسية تراجع البحث فى الكيانات البشرية.

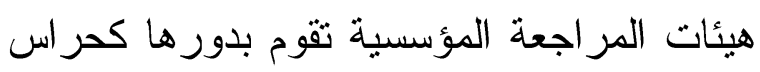

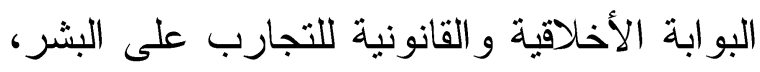
وترشد الباحثين الى مسائل من قبيل الحصول الحانه على الموافقة عن علم ، و الحفاظ على الاسرار و الخصوصية ، وتطوير تصميم البحث. تستخدم عن ولطي الاسرار

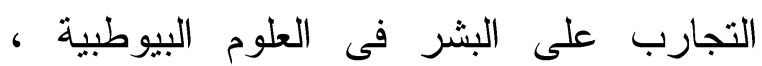
وبالمثل فى كثير من العلوم الاجتماعية كعلم النفس ، و الأنثروبولوجيا ، و علم الاجتماع.

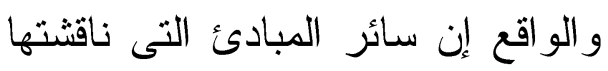
آنفا من الممكن تسويغها عن طريق النظريات الإخلاقية التى تؤكد أهمية حماية الحقوق الفردية و الكرامة الإنسانية. وتقام النزعة الكانطبة أقوى وأسلم تسويخ لهذه الارشادات: إذ إنه من الممكن

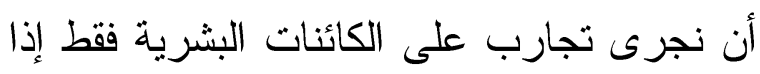
اتبعنا قواعد حماية الكرامة الاستقلالية وحقوق

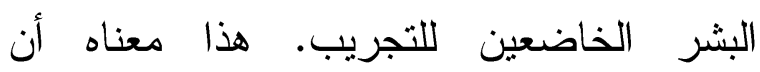

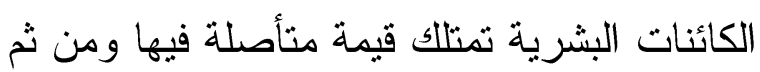
يجب ألا نجعلها حقل تجارب. على الجانب الآخر ، بعض هذه القواعد قد تعوق التقام 


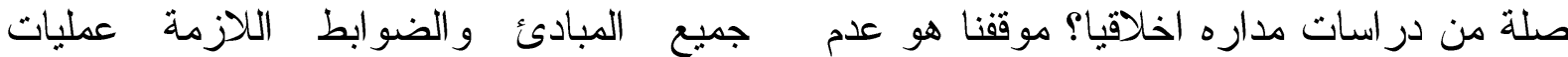
نشر بيانات متحصل عليها من دراسة غير التجريب الحيوى ، وضرورة ألا تطغى رغبات اخلاقية ويجب تجاهلها. المسألة ، و على الرغم الباحثين والفنبين الابستمولوجية على رغبات المجتمع بشكل عام (rr) من ذلك ، تبقى جدليه.

ويعتبر إعلان هلسنكى من اهم

النصوص التى صيغت من جانب الجمعية الطبية العالمية فى هذا المجال وقد أعيد صياغته فى عام سرو ام وهو بحتوى على : 1- يجب على البحث الطبى الحيوى الذى يتتاول حالات بشرية أن يمتثل للمبادىء العلمية المقبولة بصفة عامة ، وعلى معرفة مستفيضة بكل ما جاء وكتب فى المراجع

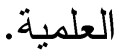

Y- ينبغى لكل تصميم و أداء بشأن إجراءات تجريبية تتناول حالات بشرية ، أن يصاغا بوضوح فى بروتوكول تجريبى يتعين إرساله إلى لجنة مستقلة تعين خصيصا لذلك بغية

القيام بفحص و إبداء تعليقاتها وتوجيهاتها. س-لا ينبغى أن تجرى البحوث الطبية إلا بو اسطة أثخاص مؤهلين علميا و المسؤولية تجاه الحالة البشرية موضوع البحث ، حتى ولو كان هذا الشخص قد أعطى موافقته على ذلك.

ع- يجب دائما احترام حق الشخص موضوع البحث فى المحافظة على سلامته. 0- إن كل مشروع بحث يتاول حالات بشرية ينبغى أن يكون مسبوقاً بتقويم دقيق للمخاطر المتوقعة بالمقارنة مع المنافع المتوقعة للشخص موضوع البحث أو لغيره.

فى عام 190 190 م تبنت المؤسسة الطبية العالمية مجموعة من المبادىء الإخلاقية للبحث و التجارب، لتكون ارشادات مهنية صممها اطباء. المؤسسة الطبية العالمية ذهبت لما وراء شفرة نومبرج حيث قدمت موافقة بديلة فى التجربة التى يكون فيها الشخص محل الدراسة مريض جدا لدرجة انه لا يستطيع الموافقة

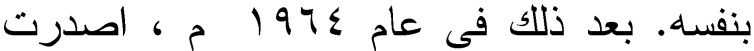
، المؤسسة الطبية العالمية تصريح هيلنسكى إسهام أساسى ميز به بين البحث السريرى الحادث بالتزابط مع الرعاية الطبية ، والبحث السريرى بدون علاج محتمل. مراجعة عام 19V0 م للتصريح احتوت المرجع الاول للحاجة الى مراجعة اللجنة لاخلاقيات البحث القائم على

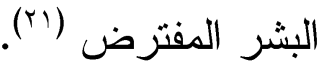

\section{إعـالاز هلسنكىى :}

ولقد سلك هذا المظهر الحيوى للأخلاق

الطبية مسلكاً ثورياً لا سيما بعد الحرب العالمية الثانية (9 9 19- 19 ( ) ) و الفظائع الوحشية التى ارتكبها الأطباء النازيون وما اعقبها من تطورات التلاعب بالمادة الوراثية ، والتلقيح الصناعى ، ونقل وزر اعة الاعضاء ، و الحبوب المجهضة ... وغيرها. ولقد أدى ذلك الى تأسيس الر ابطة الطبية العالمية و المعاهدة الدولية المعروفة بإعلان هلسنكى والتى احتوت على 
ع- إذا رأى الطبيب أنه من الضرورى بمكان عدم الحصول على موافقة الشخص المعنى المستتدة على العلم بأبعاد الأمر تعين عليه تبيان الأسباب الخاصة بذلك فى بروتوكول التجربة ، بغية عرضه على اللجنة المستقلة. 0- يمكن للطبيب أن يقرن البحث الطبى بالعناية المهنية ، بهدف اكتساب معارف طبية جديدة وعلى أن يقتصر ذلك على الحالات التى يكون فيها البحث الطبى له مبرر من حيث

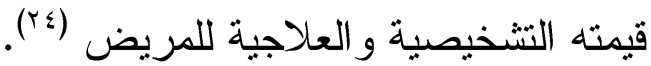
ثـــروط البحث الطبى غير العلاجى الذلى يتناول

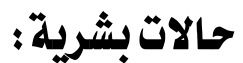

1-فى حالة التطبيق العلىى للبحوث الطبية التى تجرى على كائن بشرى فإنه من واجب الطبيب أن يظل هو الحامى لحباة وصحة ذلك الثخص الذى يتم إجراء البحث الطبى لـى لهاءئ

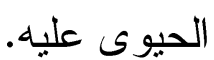

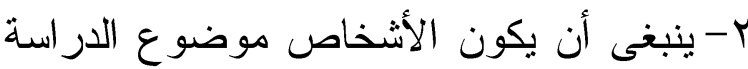

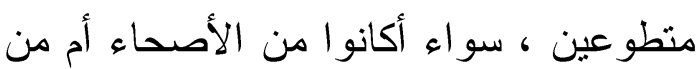
المرضى ، الذين لا صلة للمشروع التجريبى

$$
\text { بمرضهم. }
$$

r-ينبغى للباحث أو للفريق البحثى أن يتوقف عن إجراء البحث إذا ما رأى أن الاستمرار فيه يمكن ان يكون ضار ا بالفرد المعنى. ع- لا ينبغى أبدا فى حال إجراء بحث على بلى بلى الإنسان أن تعلو مصلحة العلم والمجتمع على الى لاءلى الاعتبارات المتصلة بخير وصالح الثخص الثص

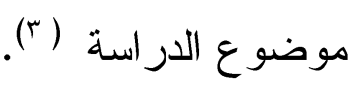

ب-يتحنم على الطبيب عند نشر نتائج بحوثه أن يحافظ على دقة نتائجه. V-V يتعين عند اجراء اى بحث على شخص ما لأه ابلاغه على نحو ملائم بالاهداف ومناهج

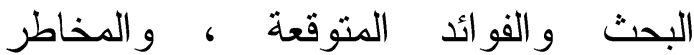
المحتملة للاراسة ، وعن المشقة التى قد تستلزمها.

^-فى حالة عدم الأهلية القانونية للشخص المعنى ، ينبغى الحصول على المو افقة من لهن الوصى الثرعى عليه وفقا لقواعد التشريع

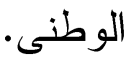
9- ينبغى أن يحتوى بروتوكول البحث دائما على بيان عن الاعتبار ات الأخلاقية المتبعة ،

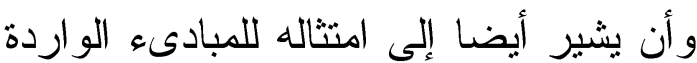
فى هذا الاعلان (rr).

\section{ثـروط البحث الطبى الاكلينيكى:}

1-يجب أن يكون الطبيب حرا لدى علاج الثخص المريض فى استخدام أسلوب تثخيص وعلاج جديد ، إذا كان ذلك فى لـى تقديره يمنح أملا فى إنقاذ حياته ، أو شفائه ، أو تخفيض معاناته.

r- إن الفوائد و المخاطر و المشقة المتوقعة من استخدام أسلوب منهجى جديد ينبغى أن يتت تقدير ها بالمقارنة بالمز ايا المتاحة من أفضل الأساليب الدنهجية التشخيصية و العلاجية

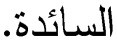
r-يجب ألايؤثر أبدا رفض المريض الاشتراك فى أى دراسة فى علاقة الطبيب بالمريض. 
المحيطة بالبحث. المنظمات العالمية للصحة المفتوحة عام ب190r ، مكنت العلماء من توظيف مرضى بأمراض معينة ومنطوعين عاديين للار اسة. الوثيقة الفدر الية الأولى بعنوان

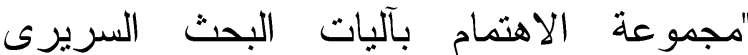
الناتجة عن الممارسة الطبية المقبولة أو لهائ المتضنة مخاطرة غير عادية" ، صدرت بحاجة إلى مراجعة لجنة البحث فى المر اكز السريرية.

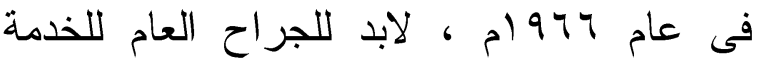
الصحية العامة فى الو لايات المتحدة ألا يتم اقرار

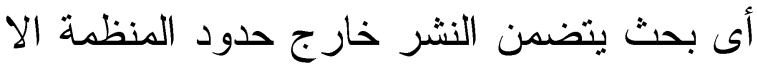
إذا راجعت اللجنة أخلاقيات العمل المقترحة. كانت اللجنة لتؤكد على ملائمة الاجراءات لحماية حقوق ومصالح الافراد الخاضعين للبحث، بما فيها اجر اءات الحصول على الموافقة المستتيرة ، والاخطار المحتملة وفو ائد البحث. المراجعات التالية لنصوص سياسة الجراح العام سمحت للجنة الضمان باعطاء "تأكيد" لمراجعة اللجنة السابقة فى منظمة واسعة القاعدة ، أكثر منها لمشاريع افراد وتطلب أن تأخذ اللجنة فى

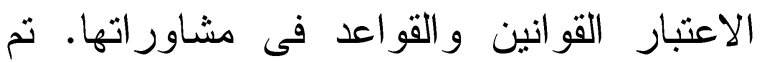
تأسيس فرع العلاقات المؤسسية للمؤسسة القومية للصحة قسم منح البحث لينفذ اوامر الجراح العام. ثم ترقية الفرع فيما بعد وتم تغيير الاسم النح إلى - وبقى - مكتب الحماية من مخاطر

$$
\text { البحث (ro). }
$$

إذن نظرًا للخطورة البالغة للتجارب الطبية وأثرها على صحة الإنسان وحياته فقد أدت هذه الأحداث وغيرها كثير إلى وضع الإنى ونيان
و إذا نظرنا إلى كل هذه المبادئ التى

وردت فى إعلان هلسنكى نرى أنها تجمع على إلى الفى الفي أهمية الحفاظ على صحة المريض الذى يقوم الأطباء بإجراء البحوث عليه ، و أيضا توضح أهمية أن يكون الثخص المبحوث على علم ودر اية بما يحدث و على نتائج ذلك و أهمينه. وتؤكد أيضا هذه البنود على أهمية إبلاغ الوصى الثرعى على الثخص غير المؤهل أو المريض بأهمية التجارب وكيف التهاع ستقام ونتائجها.

تصريح هلنسكى ، والذى روجع مؤخرا في عام 1919 م، هو أحد مجموعات

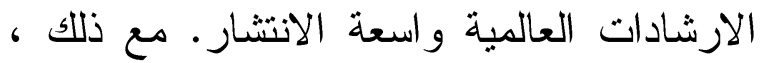
هناك جهود كبيرة أخرى مستمدة لمخاطبة الاهتمامات العالمية المتشاركة حول اخلاقيات البحث. مثلا ، مركز المنظمات العالمية للعلوم الطبية ومنظمة الصحة العالمية عقدت مؤتمر وقدمت ارشادات أخلاقية عالمية بشأن مجموعة من المواضيع منذ بها9 ام. رعاية مركز المنظمات العالمية للعلوم الطبية ومنظمة الصحة العالمية فى تطوير ارشادات اخلاقيات البحث اكدت الاهتمام العالمى بهذه المو اضيع ، لكن لا لا لهابل

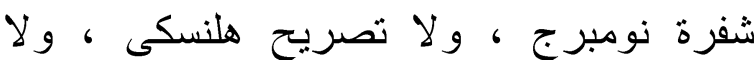
ارشادات منظمة الصحة العالمية له قوة قانونية

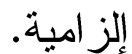
فى الولايات المتحدة ، التزايد قبل الحرب العالمية الثانية فى موارد البحث المتاحة عبر الكونجرس إلى المنظمات العالمية للصحة تز افق مع اهتمام متزايد بالمشكلات الاخلاقية 
السنين ، بما فيها ، مثلا ، دراسة توسكيجى سيفليز والتى أعيق فيها العلاج عن الانسان الامريكى من اصل افريقى الفقير و الذين لم يعرفو ا انهم جزء من مشروع البحث على المدى البعيد بطبيعة المرض المدار بواسطة الخدمة

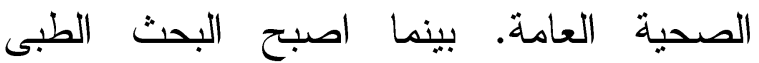

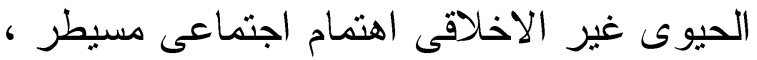

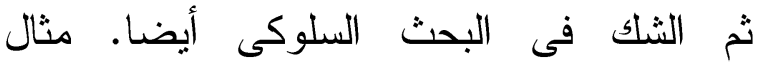
كلاسيكى لمثل هذا البحث هو التجربة التى اجريت فى جامعة بالى على ظروف "الطاعة و العصيان" ، والتى تم اقتياد الطلاب فيها للاعتقداد أنهم يديرون صدمات كهربية ضارة

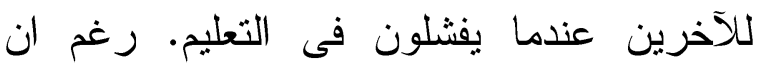
الطلاب كانو | "مستجوبين" (اخبروهم انهم خدعوا و لا يوجد صدمات حقيقة) ، يزعم البعض أن الصدمة النفسية لادر الك أن سلوك الفرد سيؤذى لئى لئن بشكل خطير شخص آخر لم يتم محوه باجر اءات الاستجو اب (rv) (بr)

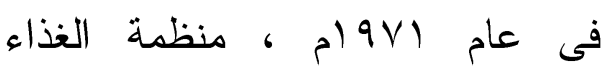
و الدواء الامريكية نشرت محددات تتطلب مراجعة دقيقة لكل الادوية الجديدة التى لا توجد موافقة عليها وكذلك الادوات المستخدمة فى الاديه

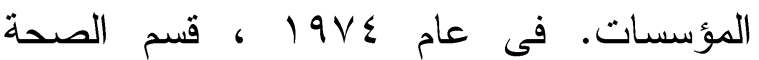
و التعليم و الثروة الامريكى اصدر المنظمات

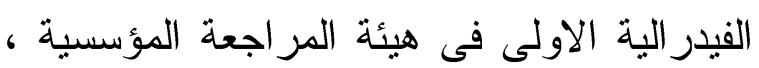
لجان ينم تأسيسها فى المؤسسات لتنفيذ المر اجعة الدقيقة التى طلبتها مؤسسات الصحة القومية عام 1974 م بناء على طلب الجر اح العام. فى نفس العام ، مرر الكونجرس تشريع البحث القومى ،
قو انين ضابطة للتجارب و البحوث الطبية. فقى الولايات المتحدة قامت السلطات الفيدرالية الأمريكية بتداول فى الولايات المتحدة لاختبار ات لات لات رقابية مسبقة لتقدير مدى فعاليتها وقياس ما قد يترتب عليها من أضرار. وفى فرنسا صدر مرسوم بr سبتمبر لو 97 ام ليشترط على منتجى

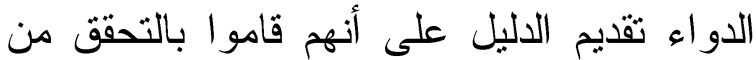
انتقاء أى ضرر عن المنتجات الصيدلية نتيجة استعمالها فى الأحوال العادية. كما يجب إثبات فعاليتها وفائدتها للمرضى. كذلك صدر مرسوم 17 ديسمبر 9V0 ام ليقنن التوجيهات الأوروبية فى صدد التجارب الطبية ، وركز على ضرورة أن تبدأ التجارب المعملية الخاصة بعلم الصيدلة ، ثم يلى ذلك الأبحاث العلاجية التى ترد على جسم

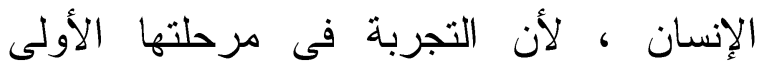
المشار إليها لا يمكن أن تقيد الثخص حتى ولو كان مستعدا لتقبلها ، لأنها فى هذه المرحلة لا لا لانيا

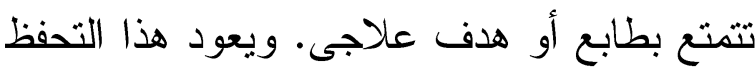
إلى اعتبار التجارب الطبية الدجردة التى ليس لها هدف علاجى إنما تتعارض مع مبدأ عصمة

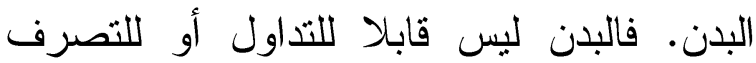
فيه (r"). أيضا فى عام 974 ام ، نشر عالم الاخلاقيات هنرى بيتشر مقاله ابداعيه فى جريدة

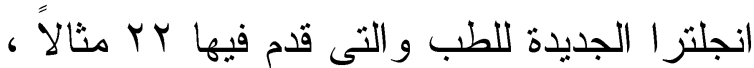
اختيروا من مقالات علمية منشورة لاجراءات البحث غير الأخلاقية قابلة للتساؤل. لاقت المقاله

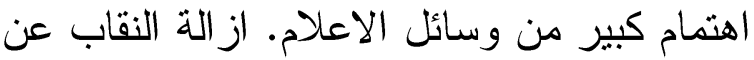
البحث الطبى الحيوى غير الأخلاقى تصاعد عبر 
القومية انعقدت لمدة اربعة ايام وفى عام IVA ونشرت تقرير بلمونت ، و الذى سمى على اسم مركز المؤتمرات بالقرب من باتليمور الذى انعقدت فيه اللجنة ، تقرير بلمونت هو ملخص موجز لثناث مبادىء أساسية لابد من استخدامها لتقييم اخلاقية البحث الذى يستخدم البشر (·r). بمعنى آخر المبادىء الأخلاقية الثلاثة الكبرى للفلسفة الأخلاقية التى تمنل أساساً لأخلاق البحث على الانسان تم بلورتها بواسطة اللجنة القومية الامريكية فى تقرير بلمونت (9 (1) ). وقد تبنتها التوجيهات الدولية لمنظمة الصحة العالمية OMS-CIMOS المبادئ عامة جدا (إنها تصلح لمواقف أخرى

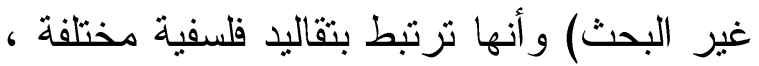
ولا تمثل أخلاقاً تشكل نظاماً بديعاً ، ما علينا "سوى تطبيقه". للمبادئ الثالثة نفس القدر من الأهمية (فلا تراتبية عندهم) ، وفى الممارسة يمكن ان يكون هناك صراع (اr). وتضدنت

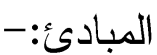

1- احترام الأشخاص ، و الذى يتطلب الحاجة لمعاملة الافر اد كأحرار وحماية أولئك غير المستقلين ، الشخص المستقل أو الحر هو

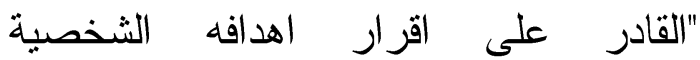
و التصرف بناء على ذللك". عملية المو افقة المستتيرة تأتى من هذا المبدأ وتتضمن مواضيع الافصاح الكامل حول دراسة موضوع البحث عن طريق محقق ، تأكيد المحقق أن المعلومات تم فهمها بواسطة
الذى - وكل هيئات المراجعة المؤسسية - نادى بتأسيس لجنة قومية لحماية الافر اد الخاضعين للابحاث السلوكية و الطبية الحيوية (^^). كذلك تم تأسيس لجنة اهتمت بهذا الموضوع باسم اللجنة الوطنية لحماية الانسان من تجارب البيولوجيا الطبية والسلوكية ، وقد وضعت هذه اللجنة قو انين صارمة لتحديد سلوك العلماء فى المعمل وتحديد أنواع البحوث المسموح بها ، وفى عام 9 ام طالب العلماء و الأساتذة فى جامهة هارفارد بالتوقف عن إجر اء تجارب بعينها - تجارب إعادة تركيب الــــ د.ن.أ D.N.A- إلى أن يتأكدوا من سلامة هذه التجارب ، وأنها لا تشكل أية خطورة على المجتمع ، وهى سابقة فى تاريخ الطب و البيولوجيا دفعت السناتور إدوارد كندى إلى أن يعلق قائلاً: "إنها المرة الأولى فى تاريخ العلم التى يوقف فيها العلماء تجاربهر لكى يعيدوا النظر فى نتائجها ، وذللك لكى يتأكدو ا ما إذا كان يجب أن يستمروا فيها. لقد كان هذا جدير بالثناء ، ولكنه كان غير ملائم ، لأن العلماء وحدهم هم الذين قرروا أن يوقفو ا نشاطهم ، وهم أيضا الذين قرروا أن

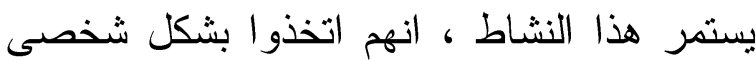
قرار يخص سياسة المجتمع ككل (9r).

\section{المبادئ الأخلاقية الكبرى}

كانت مهمة اللجنة القومية تحديد

المشكلات عند تتفيذ الالتز امات الحكومية للسلوك الاخلاقى للبحث المستخدم للبشر كمواضيع للبحث و اقترح طرق حل هذه المشكلات. اللجنة 
مبدأ الاحسان (أو عدم الاساءة) يرتبط بتراث أخلاق الخير و السعادة. هذه الأخلاق تسمى الإنى نتائجية لأنها تحكم على النوعية الأخلاقية لفعل ما بالخير (أو بالشر) الذى ينتج عنه. و القيمة الخلفية هى الرفاهية ، و الجماعة الأخلاقية تشمل هنا كل الكائنات التى تحس

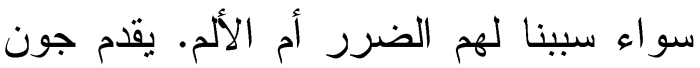
ستيوارت ميل J.S. Mill صيغة كلاسيكية

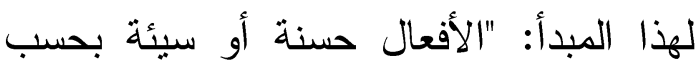
ميلها إلى زيادة الرفاهية أو إلى إنتاج الشقاء".

ينشأ الكثير من قواعد الأخلاق الطبية عن هذا المبدأ. من الجانب السلبى (عدم الإساءة) ، انه الحكمة القديمة (أولاً عدم الإيذاء) ، وما لها لهابل يقترن بها من قواعد الحذر ، ومن الجانب الإيجابى (الإحسان) ، كل العناية الطبية فى لهى

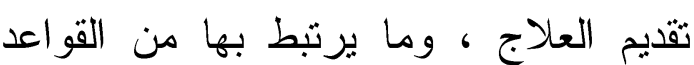
العلاجية. الاختيار الصعب أمام الطبيب الباحث هو انه لا يستهدف نفس الخير بوصفه باحثًا وبوصفه طبيباً ، ومصلحة العلم

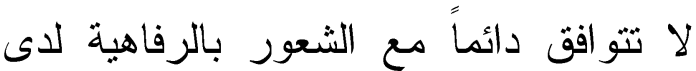
الأشخاص الخاضعين للبروتوكو لات. وهو ما يسبب صعوبة الموازنة (التى يحللها تقرير بلمونت Rapport Belmont) بين المخاطر أو الفو ائد الخاصة ببحث معين («ُ). r- العدالة ، و التى تتطلب العدل فى توزيع كلا من المنافع و إجمال البحث - وخاصة "الإهمال" أو مخاطر البحث لا يتحملها فقط

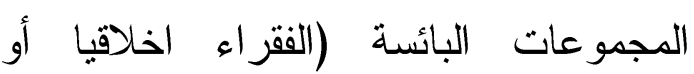

الثخص الخاضع للبحث ، وأن مشاركته تطو عية (rr). مبدأ احترام الأشخاص فى استقلالية قرارهم يرتبط بالتزاث الأخلاقى عن الواجب (أخلاق المهنة) التى تحكم على القيمة الأخلاقية لعمل

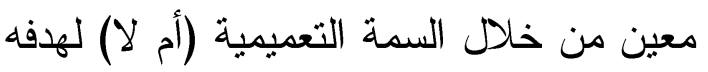

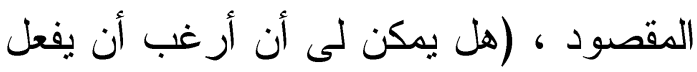

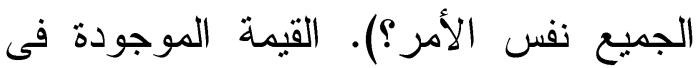
الخلفية هنا هى حرية الذات الأخلاقية التى التى لإنى تتساعل عما يجب الرغبة فيه ، و الجماعة الأخلاقية تشمل كل الكائنات "العاقلة" ، أى أى اولئك القادرين على الحكم بأنفسهم على ما لإلها ينبغى عليهم عمله. وهناك صيغة مشهورة

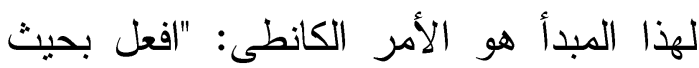

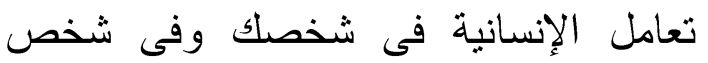
الغير فى الوقت نفسه كغاية وليس مجرد وسيلة". تتبع قاعدة المو افقة من هذا المبدأ ، مثل قاعدة عدم الكذب. أن نعلم شخصاً بما ننتظره منه ونطمئن إلى مو افقته يعنى اظهار

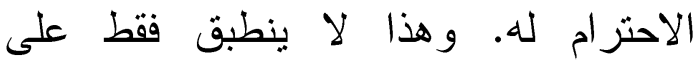
الخاضعين للبحث. فالباحث الذى بتلاعب به رئيسه فى العمل هو باحث لا يحظى لإنى لناعئ

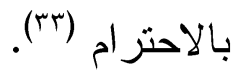
r- الاحسان ، مبدأ مبنى على بديهيات أبقراط

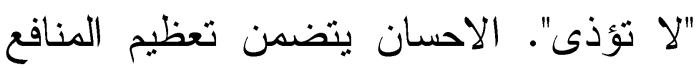
وتقليل الضرر. هذا المعيار الاخلاقى يتطلب ان الهخاطر التى يتعرض لها الثخص الخاضع للبحث هى منطقية بالنسبة الى لى لإنية المنافع المتوقعة. 
مراجعات منظمة الغذاء و الدواء الامريكية ومحددات قسم الصحة و التعليم و الثزوة الامريكى بشأن حماية الاشخاص الخاضعين للابحاث كانت قد تمت. بنيت المراجعات على اسس اخلاقية تم تحسينها منذ الحرب العالمية الثانية ووضعت اجراءات محددة لابد من اتباعها. مثنا ، حددت هذه المحددات أصغر حجم وتتكوين لهيئات المر اجعة المؤسسية - خمسة أعضاء ، منهر شخص لا ينتسب الى المؤسسة وواحد لا يهنت بالمسائل العلمية. القو اعد ايضا حددث فئات للبحث ، مبنية اساسا على المخاطر المحتملة للشخص موضع التجربة ، والتى لها مستويات مختلفة للمر اجعة. بعض أنواع البحث (السجل الطبى ، أو الاحصاءات الحيوية تبحث بدون مفهوم كيان الفرد) تتطلب تدقيق أقل من غيرها (أول استخدام لادوية السرطان على البشر). العناصر الاساسية للموافقة المستتيرة ، الظروف التى يتم فيها الحصول على هذه الموافقة ، تم رسمها بالتقصيل. اخيرا ، فئات المجتمع الخاصة المستهدفة مثل الاطفال و المساجين تم تعريفها وتم تحديد احتياجات اضافية لاخضاعهم للابحاث. تم مراجعة المحددات مرنين - مدة لدمج التغيرات بعد الخبرة فى تطبيقها وبعد ذلك لتمديد سلطتها لأبعد من مؤسسات الصحة القومبة لبعض الكيانات الحكومبة الاخرى ايضا (بَr).
الاقليات العرقية) عندما تكون المزايا سوف تعود بالنفع على الجميع. مبدأ العدالة ، أو الإنصاف برتبط بنظريات أخلاقية لا تهتم بوضع معايير للأفعال الفردية بقدر ما تضمن تعايشها السلمى. وأخلاق البحث على الانسان تأتى أساساً من مشكلات العدالة التوزيعية ، أى مشكلات الاقتسام المنصف. لقد تم التوقف عن إجراء أبحاث تغذية على مرضى عقليين فى على مستشفى نفسى (كان سكان ملاجىء المجانين يساهمون كثير اً فيما مضى فى الأبحاث حول الفيتامينات ، على سبيل المثال) لأنه تم الاعتر اف بأنه من الظلم أن نضع على عاتق مجموعة سيئة الحظ عبء البحوث التى من المفترض أن تفبد كل البشر ، ويمكن لها أن تتم على بشر عاديين. فى المقابل سيكون هناك عدم إنصاف إذا لم تجر أبحاث حول الأمر اض النفسية بمساعدة المرضى العقليين. يترتب على مبدأ العدالة قواعد عدم الاستغلال مثل تلك التى صاغتها منظمة الصحة العالمية. وهكذا ليس من حق أحد أن يجرى تجارب لدى آخرين مالا يريد أن يجريه لديه. أو أيضاً: من غير المقبول أخلاقياً أن تقوم بلد غنى بتجربة مصل فى اله بلد فقير وحين يصير المصل فعالاً يفيد أساساً (على سبيل المثال بسبب تكلفته العالبة) سكان البلاد الغنية (ro). هذا المبدأ يتطلب اختبار الشخص بطريقة متساوية. فى عام ا91 ام ، معظم 
و الحقيقة أن الاتجاهات التى تدين

التجارب إنما تلفت النظر إلى أن مبدأ التى

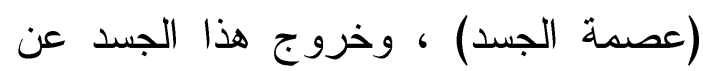

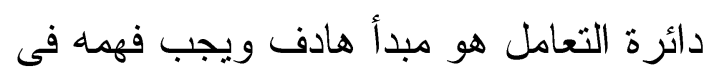

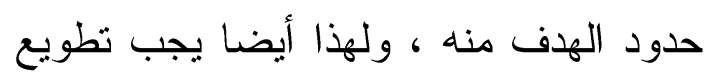

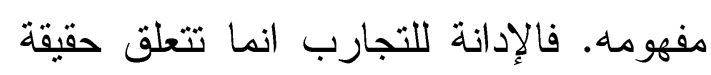
ليس بمحل التعامل وهو جسم الانسان وانما بحياة الانسان المرتبطة بهذا الجسد. لذلك ولك التهان يصح القول أن جسم الانسان يجوز ان يكون الان لهان محل للتعامل التجريبى ، وان القانون حاليا يجيز ذلك ، ولكن بشرط أن يكون الهدف أنسان

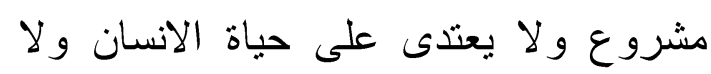

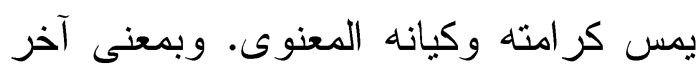
فإن القيمة الخاصة لحياة الانسان وسلامته وكنه الجسدية انما هى الدحرك و الحافز الاساسى النى

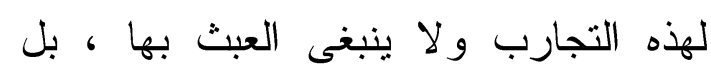
يجب أن تكون محمية ضد أى إعتداء ومن لهن

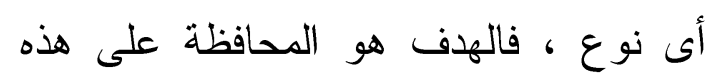

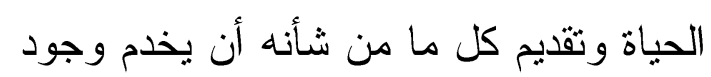
الانسان ، فى الاطار المشروع دينيا واخلاقيا

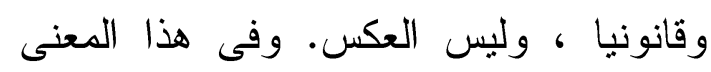
تجب الاشارة إلى أن الاهتمام بجسم الانسان يجب أن لا يكون باعتباره وعاء عارضا الإنيا

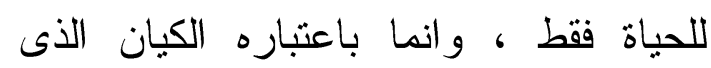
تزتبط به مجمو عة من القيم المتعلقة بالكر امة

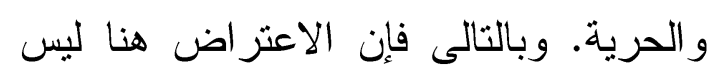

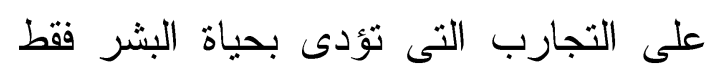

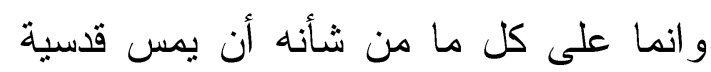

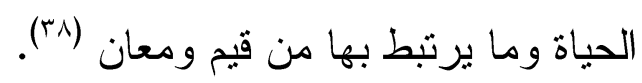

مر اعاة كل هذه المبادئ معاً ليس

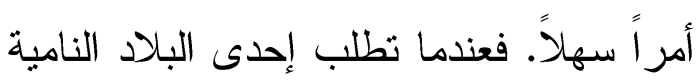

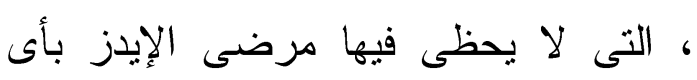

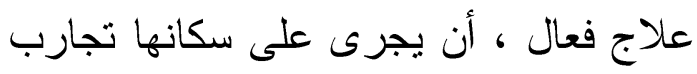

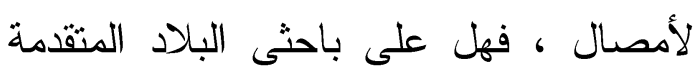

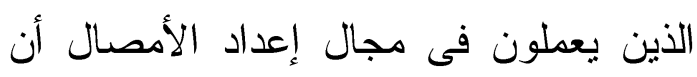

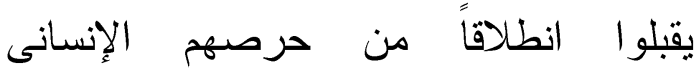

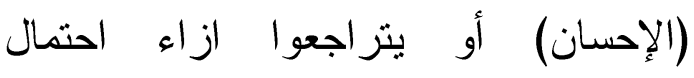
الاستغلال (عدالة)؟ وبوجه عام حينما يثقام

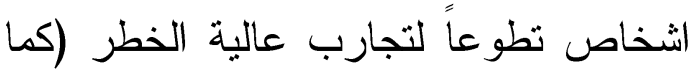

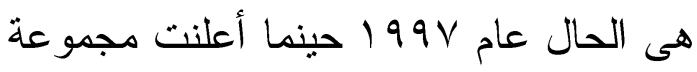

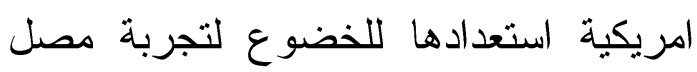
ضد الايدز من خلال لقاح حى مخفق) ، هل

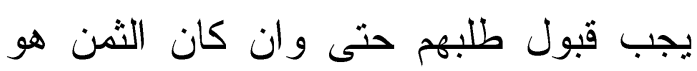
إنكار وضعهم بوصفهم اشخاص مسئولين؟

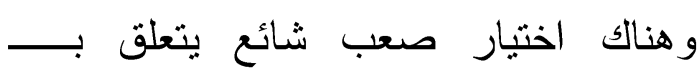

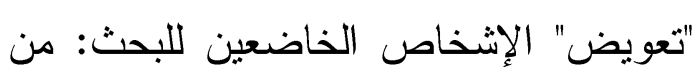
الظلم ألا يستقبد الاشخاص الخاضعين للبحث

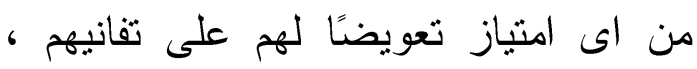
ولكن اذا كان التعويض كبيراً عد تحريضاً على الاشتر الك ، وهو ما يجعل المو افقة غيض كيرا

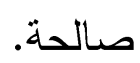

إن الحكم الأخلاقى يبحث مع كل

حالة على حدة على نقطة النوازن بين الاقتضاءات المختلفة التى تليق بالوضع على على التى

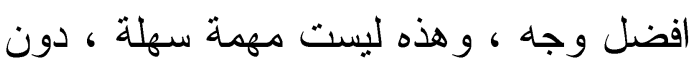

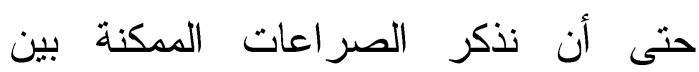
العقلانية الأخلاقية و العقلانية الاقتصادية و السياسية(rv). 
بالتحديد ،المحددات الخاصة "باعاقة التأسيس العقلى" لم يتم الانتهاء منها لأنها لم يتم التوافق بشأنها. وبناء عليه ، صارعت هيئات المراجعة المؤسية مع الابحاث

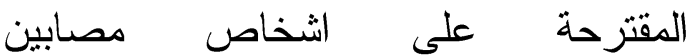
، بالشيزوفرنيا و اختلالات عقلية اخرى بخاصة عندما يتضمن البحث "محو" الفترة السابقة لتجربة الدواء الجديد (مثل: يتم ايقاف دواء مؤثز لتقييم نتائج الدواء الجديد) الاختز اقات العلمية والتقنيات الجديدة ، منل تغيير القواعد و القيم الاجتماعية ، أيضا تحدث هيئات المراجعة المؤسية لصياغة احكام بشأن مواضيع لـ يتم مخاطبتها فى المحددات. كثير من الدراسات المآخوذة على انها جزء من مشروع الجينوم البشرى ، المصممة لتجد مواقع كل الجينات فى الجسم

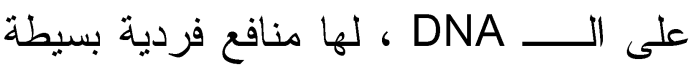
للاشخاص الذين شاركوا فيها ، لكن المخاطر الاجتماعية و الاقتصادية مثل قدر ات الاقر اد موضع التجربة ، او افر اد عائلاتهم ، للحصول على او الحفاظ على التأمين الصحى عظيمة (·؛).

ولكن نرسم خطاً فاصلاً ، فى هذا

التوسع فى البحث ، بين ما هو مرغوب عادة وبين ما لا يجب السماح به ، ينبغى ان يكون لدينا مبدأ للحكم يستخدم أخلاق "حقوق الانسان" كمرجعية. على الاقل هذه هى حالة "الاعلان العالمى عن الجينوم البشرى وحقوق الانسان" الذى تبناه المؤتمر العام
وفى اطلى هذا المفهوم السابق

يتعين تقبل التجارب الطبية ذات الهدف العلاجى. فذه التجارب بحم هدفها المشروع و المفيد لصاحب الثأن تعتبر مشروعة وغير ماسة لحياة الانسان ولا كر امته. وهو ما يذكرنا بالمادة الثالثة من اتفاق المبادىء الأوروبية الصدارة سنة •190 و التى نصت على: "حماية الانسان ضد كل تعامل غير انسانى او مهين للكر امة الانسانية". وقد أتبحث الفرصة أمام اللجنة الأوروبية لحقوق الانسان ان تصدر حكما سنة س1911 فى قضية تتعلق بعلاج طبى له طابع التجربة ، حيث اكدت اللجنة ان العلاج الطبى التجريبى و الذى يتم دون رضاء صاحب الثأن يعتبر مخالفا لقوانين حقوق الانسان. وقد أشارت اللجنة أيضا إلى ضرورة تحقق الهدف العلاجى للتجربة الطبية ، وأن التجربة الخالية من أى هدف علاجى للشخص تشكل مخالفة للحق فى احترام السلامة البدنية. وان استقلالية الانسان وحقه فى الرفض انما بعدا ضمانتين للحفاظ على سلامة الانسان و احتر ام كر امته

على الرغم من التحديد النسبى للمحددات الحالية الحاكمة للافر اد الخاضعين للابحاث ، كثير من عناصر مراجعة نظام هيئات المر اجعة المؤسسية لم يتم ، وربما لم يكن ، عمل اللجنة القومية على الأفراد المستهدفين لم يتم تتفيذها بشكل كامل ، 
تقدم الباحثان بطلب براءة بالسلسلة الخلوية المصابة ، آملين فى الكشف عن سر هذه به المقاومة للسرطان. وقد حصلو ا على البر اءة فى عام 1990 م • وبعد مضى عدة أشهر اكتشفت مجموعة كندية وجود البراءة ونشروا بياناً فى الانترنت يتهج الولايات

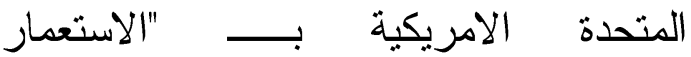
البيولوجى": فقد تم سرقة الجينوم الخاص الهرد بقبائل البابو! و انتشرت الفضيحة فى كافة ارجاء الكوكب. ثم اتضح بعد ذلك ان هؤلاء البابو كانوا على علم من خلال الباحثين بنيتهم فى طلب البراءة ، و أنهم تتاقشو ا فى هي الامر ووصلوا الى اتقاق بين القبيلة و الباحثين. اذا كان قد تم الحصول على البراءة ، و اذا تم التعرف على عامل جينى مهح ، و اذا نتج عن ذلك تطبيق علاجى ذى

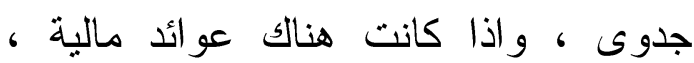
اتفقوا على ان يتقاسموا فيما بينهم هذه

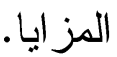

تطرح هذه القصة على بساطتها

سلسلة كاملة من أسئلة الفلسفة الأخلاقية. جينوم فرد ما ، هل هو مير اثه البيولوجى ، أو عنصر من الميراث الانسانى؟ لمن تتنمى هي هئر الخلايا التى سيتم العمل عليها فى المعمل؟ وما الذى يثبت أن القبيلة التى جاءت منها الخلايا قد حصلت على نصيبها من الفوائد المالية المحتملة التى يأتى بها تطوير التطبيقات الصناعية للاكتشاف ، فى حالة ما يكون هناك اكتشاف؟ وفى المقابل ما الذى
للبلاد الاعضاء في اليونسكو عام 199V. يصف هذا النص الجينوم البشرى بأنه "ميراث الإنسانية" ويريد حماية هذا الميراث فى اطلى حقوق ومسئوليات الاشخاص و التضامن الدولى. يدعو هذا النص باسم حقوق الانسان فى آن إلى: حرية البحث

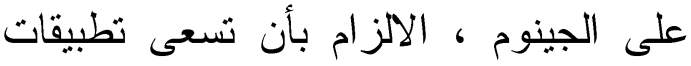
هذا البحث الى "تخفيف المعاناة وتحسين صحة الفرد و الانسانية بأسرها" ، ومنع ممارسة اختبار أو عملية جينية على شخص بله أو على شخص أو على جزء مأخوذ من جسم شخص ، دون "مو افقته المسبقة و الحرة و المستنيرة" (إلا فى حالات خاصة ينص

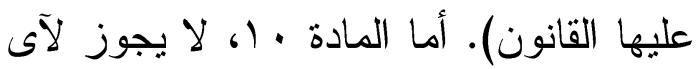
بحث يتعلق بالجينوم البشرى ولا تطبيقاته ، وبوجه خاص فى مجالات البيولوجيا و الجينات و الطب أن تكون له الأولوية على احتزام حقوق الانسان والحريات الاساسية

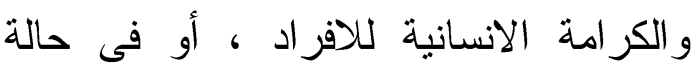
الاقتضاء ، لمجمو عات من الافر اد (1؛). سوف نشير إلى نوع المشكلة الأخلاقية التى يمكن أن تنشأ اليوم بقصة مختصرة. باحثان امريكيان ، أحدهما كان يعمل لدى قبائل البابو فى غينيا الجديدة منذ حو الى عشرة أعوام ، اكتشفا أن الخلايا الدموية لانسان ينتمى لقبيلة من البابو كانت مصابة بفيروس HTLV-1. هذا الفيروس يسبب فى العادة حالة خطيرة من اللوكيميا. فى حين أن هذا الانسان لم يكن مريضاً. 
للسلطات المسؤولة فى المجتمع المتخلف و لأبناء هذا المجتمع.

الكسب المادى غير العادل من أدوية تباع الى مجتمعات الدول النامية بينما تكون قد نمت در استها على افر اد من هذه المجتمعات. ويطالب بعض المهتمين باخلاقيات التجريب على الانسان الجهات المشرفة على بحوث خاصة بالعالم المتقدم ، بينما هى تجرى فى الدول النامية بما يلى بلى التأكد من تمتع الاشخاص الذين تجرى عليهح التجارب بالخدمات الطبية المتعلقة بالبحث. التعويض عن أذى ينتج من بحث. بناء قدرات بحثية فى المجتمع (أو البلد) الذى تجرى فيه التجارب (r^).

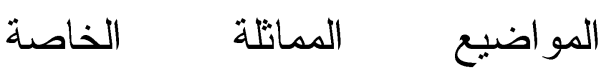
بالخصوصية تثو اجد فى البحث داخل تناذر نقص المناعة ، متزاوح بين دراسات علم الاوبئة الاساسية للانتقال الى المحاولات السريرية لايجاد طعوم وعلاجات لمرض الايدز. بينما تعتبر الابحاث الجينية والابحاث على الايدز

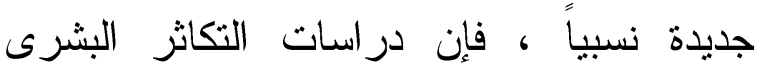
عرضتها بشكل تقليدى هيئات المراجعة المؤسسية فئى القرارات الاخلاقية بصعوبة. عندما كانت تقنية التخصيب الانبوبى جديدة ، كان هناك اسئلة بشأن اذا ما كان يجب نطبيق هذه التقنية على الازواج فقط ، وما اذا كان امتلاك اجنة مجمدة قرار صائب عندما يكون الوقت بين الاخصاب و الزراعة كافى ليتضمن

$$
\text { احتمالية طلاق الزوجين (؛؛). }
$$

يبرر أن مانح الخلايا ليس له أى حق فى أى ربح نابع من استخدام عنصر من جسده؟ و اذا توصلنا الى التعرف على عامل جينى للحماية من السرطان ، هل سيكون من المقبول أخلاقياً السعى إلى انتاج سلسلة من هن هن الكائنات البشرية تمتلك هذا العامل فى إى الجينوم الخاص بها؟ او ينبغى الاقتصار على تجارب العلاج الجينى على الاشخاص المرضى باللوكيميا (rع).

إذن ظهر مؤخرا اصطلاح imperialism ethical الاستعمار الأخلاقى ليصف بعض الممارسات التى تصدر عن مسؤولين او جهات فى بلدان متقدمة تجاه تجريب الدواء على اشخاص او جماعات فى البلدان المتخلفة (البلدان النامية). ومن الممارسات التى تدخل فى اطار الاستعمار

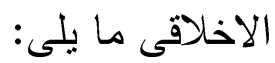
إجراء بحوث على افراد فى البلدان النامية فى حين انه بمكن اجراؤها فى البلدان المتقدمة. التساهل فى تطبيق الشتر اطات الاخلاقية عند اجر اء اختبار ات فى الدول النامية. اجر اء مشرو عات "البار اشوت" و احيانا تسمى مشروعات الهليكوبتز ، و التى يقصد بها استخلال المجتمع المتخلف باجراء ابحاث على اعضاء المجتمع ونقل نتائج هذه الابحاث الى العالم المتقدم دون اتاحة هذه النتائج او فو ائدها او التطبيقات الناتجة عنها 
مشاكلها قاصرة للغاية حتى فى الدول المتقدمة. ففى دراسة قامت بها الكلية الأمريكية للتوليد و أمراض النساء تبين أن الغالبية العظمى من النساء الأمريكيات تتقصهن بشدة المعلومات الكافية عن أمن أساليب منع الحمل المنوافرة وبخاصة الحبوب ومدى فعاليتها (0؛). أما النساء اللائى يعتبرن غير خصبات

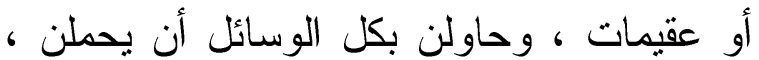
فيصبحن بلا حول ولا قوة ويشعرن بالعجز التام و الإحباط أمام الأطباء الذين لا يقدمون المساعدة

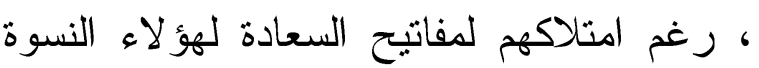
عن طريق تحقيق الأمومة لهن. ويلاحظ هذا بصفة خاصة فى دول العالم النامى حيث تكون القيمة المنظورة للمرأة وكذلك تقديرها لذاتها مرتبطين فى اغلب الاحيان بإنتاجها للاطفال.

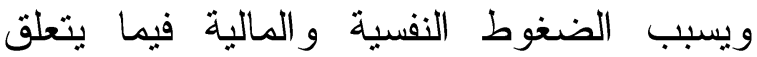
بالاخصاب في الانابيب ذات الاحتمالات الايجابية الضعيفة ، فقد اصبح واضحا ان تقييم

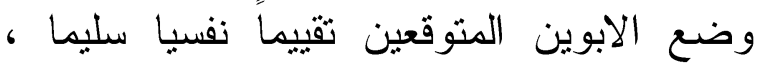
وكذا امكانية تقديم النصيحة و المشورة لهما ، من الامور الضرورية لاحترام حقوقهما الانسانية. ولقد اعترف مكتب الكونجرس الامريكى للتكنولوجيا و القياس بصفة رسمية بأن النصح و المشورة امر مهم للغاية ولكنه احد المكونات التى تستخدم غالبا اقل مماينبغى فى علاج العقم او عدم الخصوبة. ولقد نشرت الحكومة الاستر الية منذ مدة أوضح اعتراف بالضغوط التى يسبيها الاخصاب فى الانابيب للنساء
تتطبق علاقة التفاعل بين الطبيب

و المريض على جميع الاستخدامات العلاجية لتقنيات الطب البيولوجية. فغالبا ما تكون النساء

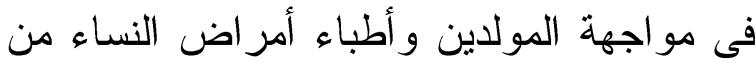
الرجال على وجه الخصوص أكثر حساسية و واظهارا للحرج و التلطف الراسخ فيهن عندما يتعلق الأمر بوظائفهن التتاسلية. فالنساء الفقير ات وغير المتعلمات يققن فى موقف ضعيف فى المى لئ تعاملهن مع الأطباء بسبب الفجوة الكبيرة التى تفصلهر عنهن ليس فقط من حيث المعلومات المتخصصة بل أيضا من ناحية المكانة والوضع لئن

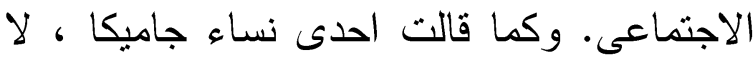

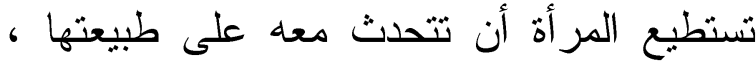
لأنه عال جدا ، وتتأنى حساسية حقوق المر أة فى أنى المعاملات العلاجية نتيجة تلهفها ومخاوفها لاتهات على اعتبار أنها طالبة مساعدة ومتوسلة من

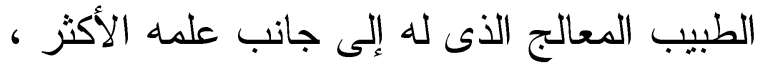

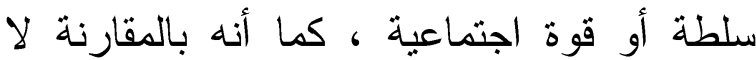
بعانى من الألم والخوف. فضلا عن أن الطبيب هو الحكم أو الوسيط المجاز اجتماعيا وثقافيا وخلقيا للأمور الصحية وله دور قد يؤثر فى الصى سلوكه كحارس لبو ابة تقنيات منع و انهاء الحمل أو الاجهاض ، وغير ذلك من الوسائل القليلة و المحدودة للعمل فى طب العقم ، على انه مرض من الأمراض. ويبلغ التعرض للمتاعب العاطفية أقصى مداه حينما لا يكون لدى المرأة وعى تام وكاف بحالتها الخاصة. ويبدو أن المعلومات العامة لدى النساء عن وظائف أعضاء الخصوبة و الانجاب ، وكيفية مواجهة 


\section{ثانياًا المراجع الاجنبية : -}

10. Charles Doughetry, "Criteria for morally acceptable research with human subjects", in Exploration in Medicine, edited by Lamb and Daries, Averbury, Brookfield, U.S.A., 1984.

11. Lewis M.A., Law and Ethics in the Medical Office, F. A. Davis Company Philadelphia, 1983.

12. Lygre, D,G., Life Manipulation, Walter \$ Company, N. Y. 1979, .

13. Mc Cormick, R.A, How Brave A New World? S.C.M. Press Ltd, England, 1981.

14. Milunsky, A, Genetics \& the Law II, Plenum Press, New York, 1980.

15. Singer, P.: Practical Ethics, Cambridge university press, Cambridge 1979 .

16. Thomson, W.A.R.: "A Dictionary of Medical Ethics \& Practice" John Wright \& Sons Limited, Bristol, 1977.

17. Wigodsky, H., Humans as Research Subjects, in, Birth to Death, Ed. Thomasma, D.C. Cambridge In Press, 1996.

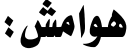

18. Wigodsky., H., Humans as Research Subjects, in, Birth to Death, Ed. Thomasma, D.C. Cambridge In Press, 1996, P. 259.

9 1. أحمد صبحى ، محمود زيدان : فى فلسفة الطب ،

دار المعرفة الجامعيــة ، الاســـندرية ، 1990 ـ ـ

$$
\text { ص • מ }
$$

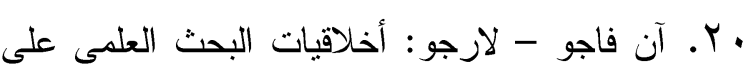

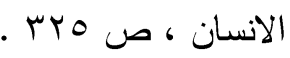

21. Wigodsky, H., P. 259.

Y Y. آن فاجو - لارجو: أخلاقيات البحث العلمى على

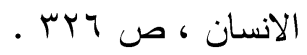

23. Wigodsky, H., P. 260.

24.Ibid. P. 131.

25. Charles Doughetry, "Criteria for morally acceptable research with human subjects", in Exploration in Medicine, edited by Lamb and Daries, Averbury, Brookfield, U.S.A., 1984. P. 130.

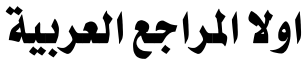

1. أحمد صبحى ، محمود زيدان : فى فلســفة

الطب ، دار المعرفة الجامعية ، الاسكندرية

.19906

r. آن فاجو - لارجو: أخلاقيات البحث العلىى

على الانسان.

ب. إيوجين برودى: تقنيات الطــب البيولوجيــة

وحقوق الإنسان ، ترجمة يوســف يعقــوب

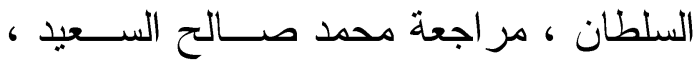

مؤسسة الكويت للتقدم العلمــى ، الكويــــ ، .1997 . 13

ع. جوث ديكسون: العلم و المشـــتغلون بالبحـــث

العلمى فى المجتمع الحديث ، ثرجمة شــعبة

الترجمة باليونسكو ، عالم المعرفــة (Y I I)

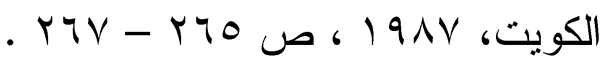

ه. جورج كانغيلام: در اسات فى تاريخ العلــوم

وفلسفتها ، ترجمة محمد بن ساسى ، مر اجعة

محمد محجوب ، مركز دراســات الوحــدة

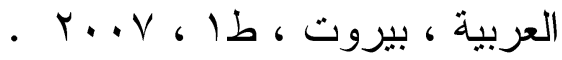

7. ديفيد ب. رزينك .

V. رزنيك : أخلاقيات العلم ، ترجمة عبد النور

عبد المنعم ، مر اجعة يمنى طريف الخولى لمرتى

عالم المعرفة ، الكويــــ ، العــدد (ب آب) ،

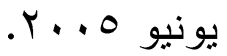

^. ناهدة البقصىى : الهندسة الور اثية و الأخلاق ، عالم المعرفة ، الكويت ، س 199 1 .

9. نبيل صبحى حنا: الطب و المجتمع ، مكتبــة

الأنجلو المصرية ، القاهرة ، و 19NV 
41. Lewis, M.A, P.117.

42. Wigodsky, H., P. 265.

43. Ibid. P. 265.

44. Lygre, D.G.: P.7 - 8 .

45. Wigodsky, H., P. 265.

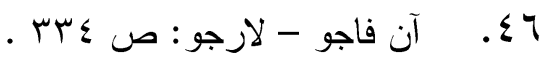

47. Wigodsky, H., P. 265.

$$
\text { 9 } 0 \text { ـ. }
$$

51. Wigodsky, H., P. 266.

$$
\text { ror }
$$

53. Milunsky, A, Genetics \& the Law II, Plenum Press, New York, 1980, P.21.

54. Mc Cormick, R.A, How Brave A New World? S.C.M. Press Ltd, England, 1981, P.283.

55. Wigodsky, H., P. 266.

$$
\begin{aligned}
& \text { 4 . } \\
& \text { OV } \\
& \text {. rrq }
\end{aligned}
$$

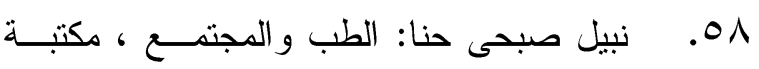

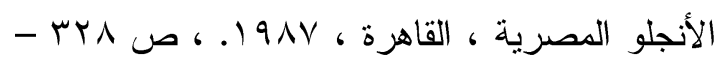

59. Wigodsky, H., P. 267.

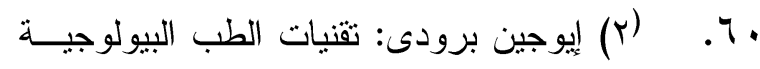

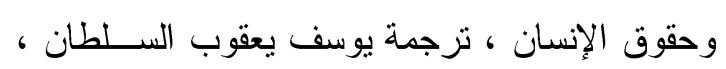

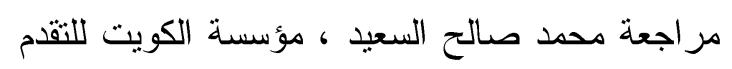

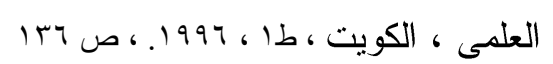

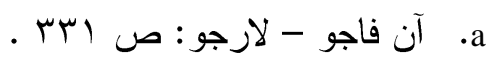

b. Wigodsky, H., P. 260.

26.Ibid. P. 261.

27.Ibid. P. 262.

28.Ibid. P. 262.

29.Thomson, W.A.R.: "A Dictionary of Medical Ethics \& Practice" John Wright \& Sons Limited, Bristol, 1977, P.191.

30.Lygre, D.G, Life Manipulation, Walker \& Company, New York, 1979, P.86.

31.Lewis M.A., Law and Ethics in the Medical Office, F. A. Davis Company Philadelphia, 1983, P. 117.

$$
\text { بس. نقلاً عن ناهدة البقصىى }
$$

33. Wigodsky, H. P. 263.

$$
\text { ع ז. آن فاجو - لارجو: ص rسז.. }
$$

35.Wigodsky, H. P. 263.

$$
\begin{aligned}
& \text { c. رزنيك : أخلاقيات العلم ، ترجمة عبد النور عبــ } \\
& \text { المنعم ، مر اجعة يمنى طريــف الخـــولى ، عـــالم }
\end{aligned}
$$

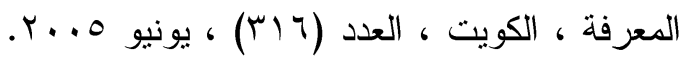

d. Wigodsky, H. P. 263.

36. Singer, P.: Practical Ethics, Cambridge university press, Cambridge 1979, P.135.

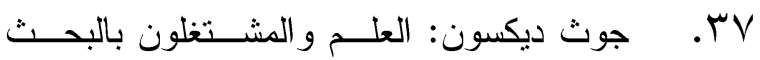

العلمى فى المجتمع الحديث ، ترجمة شعبة الترجمة

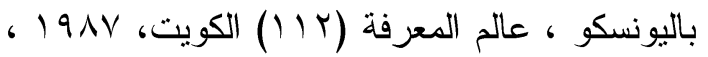

$$
\begin{aligned}
& \text { ص rTV-rTo }
\end{aligned}
$$

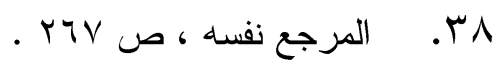

$$
\begin{aligned}
& \text { q". المرجع نفسه ، ص }
\end{aligned}
$$

40. Wigodsky, H., P. 264. 